\title{
Haptic perception: A tutorial
}

\author{
S. J. LeDERMAN \\ Queen's University, Kingston, Ontario, Canada \\ AND \\ R. L. KLATZKY \\ Carnegie Mellon University, Pittsburgh, Pennsylvania
}

\begin{abstract}
This tutorial focuses on the sense of touch within the context of a fully active human observer. It is intended for graduate students and researchers outside the discipline who seek an introduction to the rapidly evolving field of human haptics. The tutorial begins with a review of peripheral sensory receptors in skin, muscles, tendons, and joints. We then describe an extensive body of research on "what" and "where" channels, the former dealing with haptic perception of objects, surfaces, and their properties, and the latter with perception of spatial layout on the skin and in external space relative to the perceiver. We conclude with a brief discussion of other significant issues in the field, including vision-touch interactions, affective touch, neural plasticity, and applications.
\end{abstract}

Haptics is now commonly viewed as a perceptual system, mediated by two afferent subsystems, cutaneous and kinesthetic, that most typically involves active manual exploration (Lederman \& Klatzky, 2009). Whereas vision and audition are recognized for providing highly precise spatial and temporal information, respectively, the haptic system is especially effective at processing the material characteristics of surfaces and objects. Here we concentrate on the behavioral research that has addressed the phenomenology and functionality of haptic perception. This excellent behavioral work stands on its own, although where directly appropriate we relate it to work in neuroscience (for more general references, consult, e.g., Kandel, Schwartz, \& Jessell, 2000; Squire, 2009).

Because this tutorial is necessarily brief, for certain topics we have also chosen to direct the reader to one or more review chapters or books that offer further detailed discussion and extensive bibliographies containing important original sources. The tutorial provides a comprehensive bibliography followed by a list of other suggested review articles, encyclopedia entries, and books about haptics and the sense of touch that the reader may wish to consult.

\section{PERIPHERAL SENSORY MECHANISMS}

The haptic system uses sensory information derived from mechanoreceptors and thermoreceptors embedded in the skin ("cutaneous" inputs) together with mechanoreceptors embedded in muscles, tendons, and joints ("kinesthetic" inputs).
Most studies that focus on human sensations involve the application of various stimuli (hairs, sharp probes, warm and cool metal tips, etc.) to the skin of a passive observer, thereby limiting inputs to those of the cutaneous receptors. In his seminal 1962 paper on active touch, J. J. Gibson emphasized the polarity of one's tactual experiences: Being passively touched tends to focus the observer's attention on his or her subjective bodily sensations, whereas contact resulting from active exploration tends to guide the observer's attention to properties of the external environment. Whereas the results of the passive-touch studies clearly confirm that cutaneous inputs alone are sufficient to induce subjective sensations, they fail to recognize the important role of cutaneous sensing when active exploration is permitted.

Cutaneous receptors are found across the body surface, beneath both hairy and hairless skin. To date, the majority of human studies have focused on mechanoreceptors and thermoreceptors located within the hairless ("glabrous") skin of the human hand (Jones \& Lederman, 2006). Figure 1 shows the structure of palmar skin, together with the specialized nerve endings of the four mechanoreceptor populations that human neuroscience has shown are distributed within this region (see Johansson \& Vallbo, 1983). The response characteristics of each population are differentiated by both the relative size of its receptive field (small vs. large) and its relative adaptation rate (i.e., response to onset/offset of skin deformation vs. continued response during sustained skin deformation), as outlined in Table 1A. Table 1B shows the relatively optimal fea- 


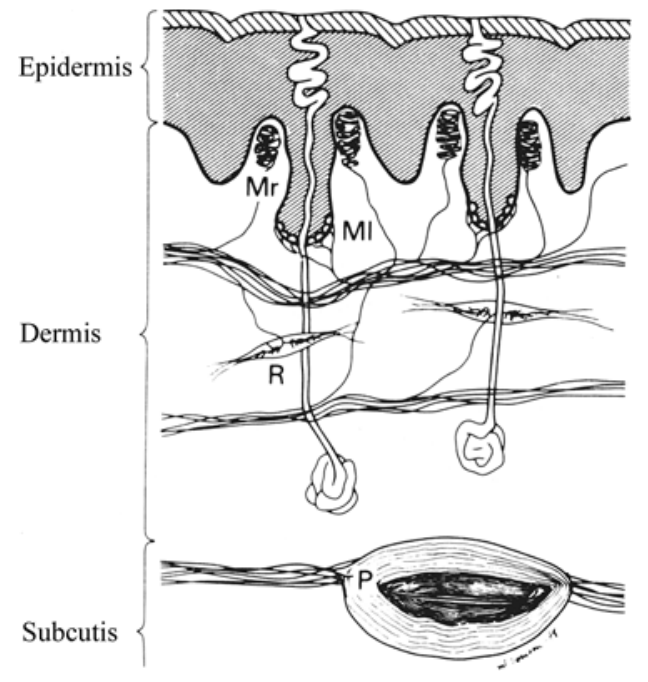

Figure 1. Vertical section through the glabrous skin of the human hand. Schematic depiction of the two major layers of the skin (epidermis and dermis), and the underlying subcutaneous tissue. The locations of the organized nerve terminals are also shown. Mr, Meissner corpuscle; MI, Merkel cell complex; R, Ruffini ending; P, Pacinian corpuscle. From "Tactile Sensory Coding in the Glabrous Skin of the Human Hand," by R. S. Johansson and A. B. Vallbo, 1983, Trends in Neurosciences, 6, p. 28. Copyright 1983 by Elsevier. Reprinted with permission.

ture sensitivity, together with the primary functions with which each mechanoreceptor population is associated. The two additional peripheral receptor populations known as thermoreceptors (Stevens, 1991) respond to increases or decreases in skin temperature, and mediate the human experiences of warmth and cold, respectively.

The kinesthetic inputs from mechanoreceptors in muscles, tendons, and joints contribute to the human perception of limb position and limb movement in space (see reviews by Gandevia, 1996; J. L. Taylor, 2009). Research in the motor-control field tends to treat kinesthetic feedback as sensory signals to be included in models (feedback, feedforward) of limb movement and grasping. Hence, we will consider the contributions of kinesthesis and kinesthetic inputs only where they are inextricably bound up with human haptic processing and representation-that is, for purposes of sensing, perceiving, and thinking about objects, their properties, and the space within which they reside.

Cutaneous and kinesthetic inputs are combined and weighted in different ways to serve various haptic functions. In the discussion that follows, we treat complex human haptic experience as being influenced by a variety of factors at multiple levels of processing. Accordingly, it is neither possible nor particularly fruitful to separate human haptic function into modular compartments as was once done (e.g., sensations, percepts, and cognitions).

\section{“WHAT" AND “WHERE” TOUCH SYSTEMS}

Touch scientists have been recently and vigorously debating whether, like vision (and audition, a more recent topic of debate), the somatosensory system is served by two subsystems, a "what" system that deals with perceptual (and memory) functions, and a "where" system that deals with the perceptual guidance of action. Evidence that supports a "what/where" distinction for the somatosensory system include, for example, fMRI and behavioral studies by Reed, Klatzky, and Halgren (2005) and by Chan and Newell (2008), respectively. Reed et al. (2005) showed that haptic object recognition and object localization activated inferior and superior parietal areas, respectively, suggesting a correlation with the distinction between dorsal and ventral visual streams made earlier by Ungerleider and Mishkin (1982). Chan and Newell showed behavioral evidence for a task-dependent what/where distinction that transcends modalities by using a dual-task paradigm. Simultaneous "what" or "where" tasks were found to mutually interfere more than crossfunction tasks in both intramodal and crossmodal conditions, indicating resource pools that depended on the task demands but not on the modality (vision, haptics) used to execute the task. Dijkerman and De Haan (2007) have comprehensively evaluated the neural and behavioral literatures for evidence of separate processing streams used for somatosensory perception versus action ("what" vs. "how" systems), as well as for distinguishing between haptic processing of external targets and sites on the body. An important issue that arises from this body of research is whether haptic processing of shape taps into a visual "what" pathway by invoking visual imagery, a topic we consider further below.

For purposes of the present tutorial, we will organize the following discussions of haptic perception in terms of this functional distinction between "what" and "where" systems.

\section{The "What" System}

The "what" system in touch processes surfaces, objects, and their many different properties. The efficacy of this processing pathway is demonstrated by the finding that familiar objects are recognized quickly and with very high accuracy by touch alone (Klatzky, Lederman, \& Metzger, 1985). The foundation for this ability lies in the sensory primitives signaled by the peripheral receptors. A broad spectrum of properties results from further neural processing of the receptor signals, with research providing considerable insight into the computational nature of that processing.

To begin with, it is useful to divide haptically accessible object properties into two broad classes: material and geometric. Material properties are defined as those independent of the particular object sample being considered; conversely, geometric properties describe the structure of that object sample.

\section{Spatial and Temporal Resolving Capacity of the Skin}

Before considering in the next section the haptic perception of object properties, it is important to be aware of the extent to which the cutaneous system is limited by its ability to resolve spatial and temporal details presented 
Table 1A

Response Characteristics of the Four Mechanoreceptor Populations

\begin{tabular}{cll}
\hline \multirow{2}{*}{ Adaptation Rate } & \multicolumn{1}{c}{ Size of Receptive Field } \\
\cline { 2 - 3 } Slow & $\begin{array}{l}\text { Slow-adapting type I (SA I) } \\
\text { (Merkel) }\end{array}$ & $\begin{array}{l}\text { Slow-adapting type II (SA II) } \\
\text { (Ruffini) }\end{array}$ \\
$\begin{array}{l}\text { Fast-adapting type I (FA I) } \\
\text { (Meissner) }\end{array}$ & $\begin{array}{l}\text { Fast-adapting type II (FA II) } \\
\text { (Pacinian) }\end{array}$ \\
\hline
\end{tabular}

Note-The terminal ending associated with each type of tactile nerve fiber is shown in parentheses. aNote that primate research has failed to find evidence for the existence of SA II units (see, e.g., Johnson, 2001). From Sensation and Perception (2nd ed., p. 302), by J. M. Wolfe et al., 2008, Sunderland, MA: Sinauer. Copyright 2008 by Sinauer Associates, Inc. Adapted with permission.

to the skin. Under some circumstances, these factors may potentially constrain haptic perception.

Over the years, a number of psychophysical methods have been proposed to evaluate the spatial acuity of the skin. Two classical methods are known as the "two-point touch threshold" and "point-localization threshold" (see, e.g., Weinstein, 1968). The two-point touch threshold represents the smallest spatial separation between two stimuli applied to the skin that can be detected some arbitrary percentage of the time (e.g., 75\%). Observers are asked to decide whether they subjectively feel "one" or "two" points. Although relatively simple to administer, the twopoint touch measure is somewhat limited, in that it not only requires a subjective response but is also vulnerable to a number of possible confounds (see, e.g., Johnson \& Phillips, 1981). An extensive research literature on this topic exists (see, e.g., Jones \& Lederman, 2006). A more objective variant of the classic psychophysical procedure (Craig, 1999; Johnson \& Phillips, 1981) requires the ob- server to decide whether a linear grating pattern has been applied "horizontally" or "vertically." Thresholds obtained with this more objective measure are typically lower than the two-point touch threshold (e.g., $\sim 1 \mathrm{~mm}$ on the fingertip, as opposed to $\sim 2-4 \mathrm{~mm}$ ).

When evaluating the point-localization threshold, a stimulus is presented to the skin, followed in time by a second stimulus that may or may not be applied to the same site. Observers are required to say whether the two stimuli occur at the same or different locations. The pointlocalization threshold is consistently lower (i.e., $\sim 1-2 \mathrm{~mm}$ on the fingertip) than the two-point touch threshold. However, the two measures are highly correlated (Weinstein, 1968), as is evident in Figure 2, which presents both twopoint touch and point-localization thresholds as a function of body locus for women. Corresponding male thresholds show similar patterns. Note that tactile spatial acuity varies significantly across the body surface, being highest on the fingertips and lowest on the back.

Table 1B

Mechanoreceptors: Feature Sensitivity and Associated Function

\begin{tabular}{|c|c|c|}
\hline $\begin{array}{l}\text { lechanoreceptor } \\
\text { Population }\end{array}$ & Maximum Feature Sensitivity & Primary Functions \\
\hline SA I & $\begin{array}{l}\text { Sustained pressure; maximally sensitive to very low frequencies } \\
(<\sim 5 \mathrm{~Hz}) \text { (Johansson, Landström, \& Lundström, 1982); spatial de- } \\
\text { formation (Johnson \& Lamb, 1981) }\end{array}$ & $\begin{array}{l}\text { Very-low-frequency vibration detection (Löfvenberg } \\
\text { \& Johansson, 1984) } \\
\text { Coarse texture perception (D. T. Blake, Hsiao, } \\
\text { \& Johnson, 1997) } \\
\text { Pattern/form detection (Johnson \& Phillips, 1981) } \\
\text { Stable precision grasp and manipulation (Westling } \\
\quad \text { \& Johansson, 1987) }\end{array}$ \\
\hline FA I & $\begin{array}{l}\text { Temporal changes in skin deformation }(\sim 5 \text { to } \sim 40 \mathrm{~Hz} \text { ) (Johansson } \\
\text { et al., 1982); spatial deformation (Johnson \& Lamb, 1981) }\end{array}$ & $\begin{array}{l}\text { Low-frequency vibration detection (Löfvenberg \& } \\
\text { Johansson, 1984) } \\
\text { Stable precision grasp and manipulation (Westling } \\
\text { \& Johansson, 1987) }\end{array}$ \\
\hline FA II & $\begin{array}{l}\text { Temporal changes in skin deformation }(\sim 40 \text { to } \sim 400 \mathrm{~Hz} \text { ) } \\
\text { (Johansson et al., 1982) }\end{array}$ & $\begin{array}{l}\text { High-frequency vibration detection (Löfvenberg \& } \\
\text { Johansson, 1984) } \\
\text { Fine texture perception (Bensmaïa \& Hollins, 2005) } \\
\text { Stable precision grasp and manipulation (Westling } \\
\text { \& Johansson, 1987) }\end{array}$ \\
\hline SA II & $\begin{array}{l}\text { Sustained downward pressure, lateral skin stretch (Knibestöl \& } \\
\text { Vallbo, 1970); low dynamic sensitivity (Johansson et al., 1982) }\end{array}$ & $\begin{array}{l}\text { Direction of object motion and force due to skin } \\
\text { stretch (Olausson, Wessberg, \& Kakuda, 2000) } \\
\text { Stable precision grasp and manipulation (Westling } \\
\text { \& Johansson, 1987) } \\
\text { Finger position (Edin \& Johansson, 1995) }\end{array}$ \\
\hline
\end{tabular}

From Sensation and Perception (2nd ed., p. 302), by J. M. Wolfe et al., 2008, Sunderland, MA: Sinauer. Copyright 2008 by Sinauer Associates, Inc. Adapted with permission. 




Figure 2. Two-point touch and point localization thresholds are shown for various body sites. Although only the data for women are presented, the corresponding data for males show close parallels in their general patterns. The data represent mean threshold values for left and right sides of the body because, with few exceptions, there was no effect of laterality. Although the point localization thresholds are usually lower than the corresponding two-point values, the measures are highly correlated. The results indicate that the more distal parts of the body are more spatially acute. From "Skin and Touch," by S. J. Lederman, 1991, Encyclopedia of Human Biology, Vol. 7, p. 55. Copyright 1991 by Academic Press. (Figure adapted from S. Weinstein, 1968.) Reprinted with permission.

Studies have typically shown a decline in spatial acuity on the fingertip with increasing age for both sighted and blind individuals (e.g., Goldreich \& Kanics, 2003; VegaBermudez \& Johnson, 2004); for a more detailed summary, see Table 1 in Legge, Madison, Vaughn, Cheong, and Miller (2008). Studies that have used more recent psychophysical procedures further reveal that tactile spatial acuity in blind subjects is typically better than in sighted subjects who have been matched for age (but see Grant, Thiagarajah, \& Sathian, 2000).

Most recently, however, Legge et al. (2008) used two newly designed spatial-acuity charts that require active exploration of Braille-like dot patterns and raised Landolt rings (Figure 3A). Their results confirmed earlier findings with sighted subjects - namely, a decline in tactile spatial acuity of almost $1 \%$ per year from 12 to 85 years (e.g., Stevens \& Patterson, 1995); in contrast, the blind showed high tactile spatial acuity that did not decline with age and that was not limited to the finger used for reading Braille (Figure 3B). Having discredited peripheral factors, they attributed this intriguing finding to central changes arising from the regular use of active touch in daily life. The broader influences of development, maturation, and aging on tactile sensing and haptic perception constitute a fascinating topic for touch scientists (see, e.g., Jones \& Lederman, 2006, chap. 9).

The spatial resolving power of the skin and the influence of such factors as body locus, age, and visual experience are relevant to our next topic, the haptic perception of object and surface properties. As will become evident, they are also critical to how well people can spatially localize contacts on the body. Relative to vision and audition, the spatial resolving power of the skin is poorer than the eye's but better than the ear's (Sherrick \& Cholewiak, 1986).

The temporal resolving capacity of the skin has been measured in a number of different ways. One common measure indicates that people can resolve a temporal gap of $5 \mathrm{msec}$ between successive taps on the skin (Gescheider, 1974). Overall, the temporal resolving power of the skin is better than that of vision, but worse than that of audition.

\section{Haptic Perception of Object and Surface Properties}

Principal material properties pertain to surface texture, compliance, and thermal quality. Geometric properties generally comprise shape and size. Weight is a hybrid property reflecting an object's material (i.e., density) and its structure (i.e., volume). To be sure, this list of properties provides a coarse cut across the material and geometric domains. Perceived surface texture might be characterized, for example, in terms of its roughness, stickiness, slipperiness, or friction. Size can be measured using a number of metrics: total area, volume, perimeter, bounding-box volume, and so on. Shape is particularly hard to characterize. As was noted above, psychophysical and neuroscientific research have deepened our understanding of how the perceptual system achieves a representation of these properties, given the sensory inputs. We next describe some of the work in these areas.

Surface texture. Among the various perceptual properties that characterize object surfaces, roughness has undoubtedly received the most attention from haptics researchers. The roughness percept reflects the properties of the surface touched in interaction with the manner in which 


\section{A}

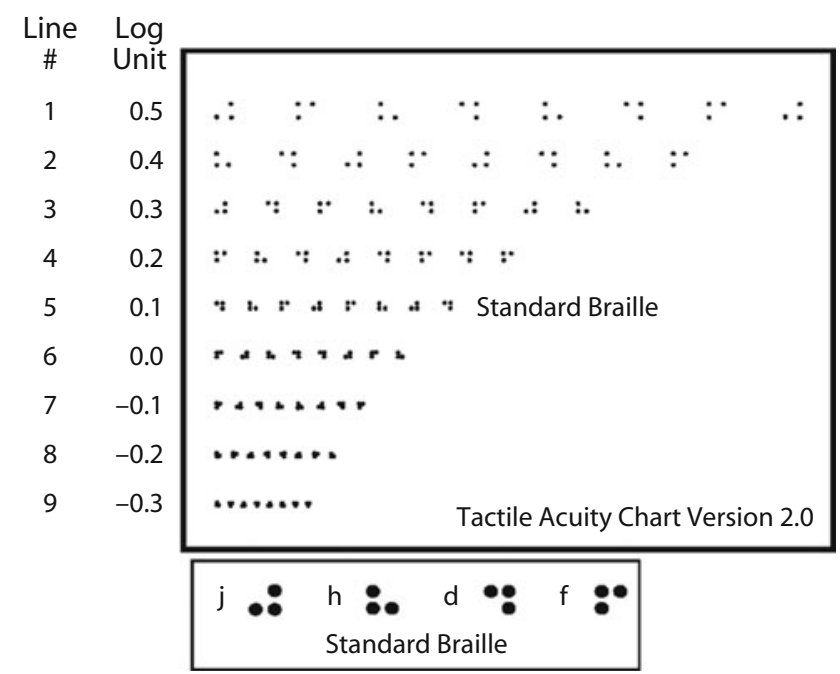

B

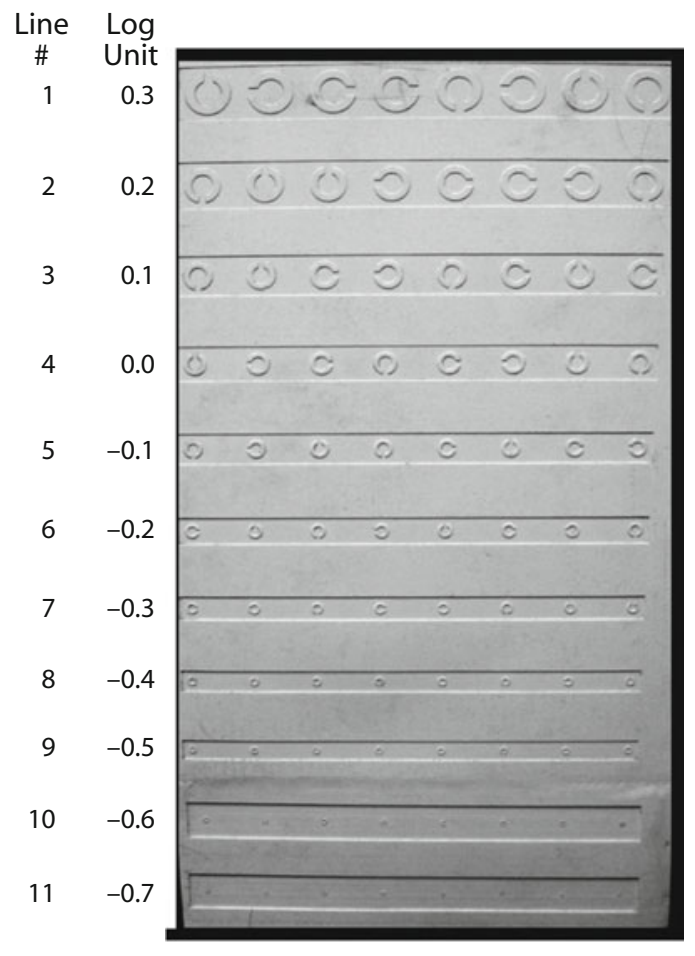

C

Dot Chart

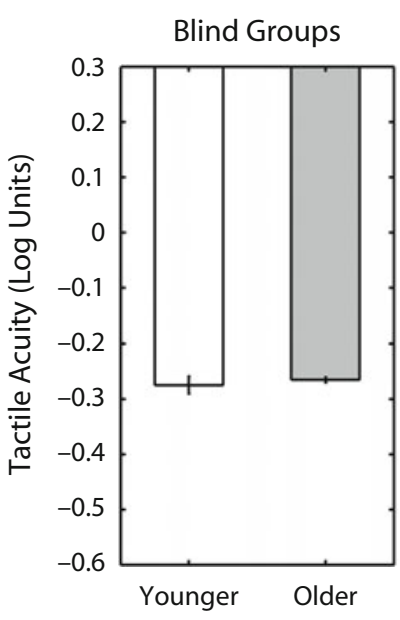

Sighted Groups

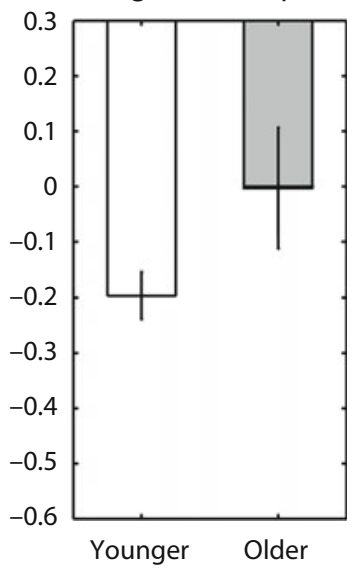

D

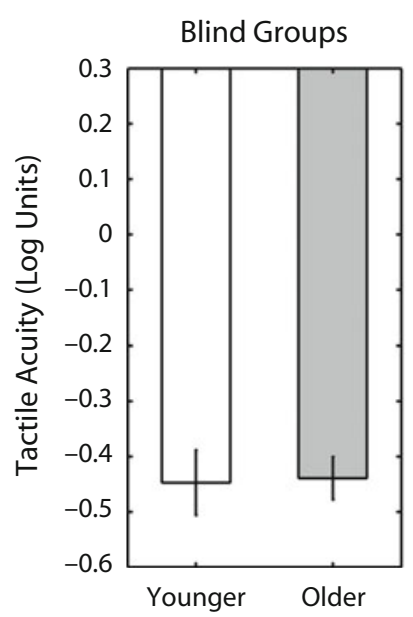

Ring Chart

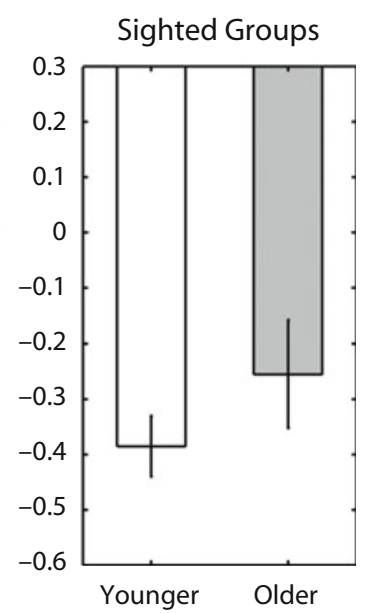

Figure 3. Newly designed dot (A) and ring (B) charts for testing tactile spatial acuity using active touch. Median tactile acuities and associated error bars indicating the interquartile range for four groups for measurements with dot chart (C) and ring chart (D) in older and younger blind and sighted subjects. From Legge, Madison, Vaughn, Cheong, and Miller (2008). Copyright 2008 by Psychonomic Society, Inc.

the surface/object is manually explored. Surface properties have been extensively studied, and one of the most important factors found to affect perceived roughness is the gap between the elements that constitute the surface; the width of the elements has a smaller effect (M. M. Taylor \& Lederman, 1975). Lederman and Taylor (1972; M. M. Taylor \& Lederman, 1975; see also Lederman, 1974, 1983) developed a mechanical model of roughness per- ception that predicted perceived roughness of linear gratings from the total area of skin instantaneously deformed from a resting position while in contact with a surface. This model used several experimental paradigms to show that the spatial distribution of the textural elements, rather than temporal factors, most strongly determined roughness perception. Neither changing hand speed (see also Meftah, Belingard, \& Chapman, 2000) nor preadapting 
the fingertip to either low- or high-frequency vibrations of high intensity (Lederman, Loomis, \& Williams, 1982) altered the perceived roughness magnitude. An additional psychophysical experiment (Lederman, 1974) confirmed that perceived roughness magnitude was determined largely by changes in groove width and less by changes in ridge width, whether or not the corresponding spatial period was varied. Because isospatial-period gratings produce the same fundamental temporal periodicity during contact, provided hand speed is constant, the results of this study suggest that temporal determinants of perceived roughness are not involved. A subsequent study by Cascio and Sathian (2001) qualified these earlier conclusions by showing that although perceived roughness of gratings is most strongly determined by the spatial variable, groove width, the smaller effect of ridge width is indirectly affected by associated changes in temporal frequency.

Subsequent to early work, a "duplex" model of roughness perception was developed, which differentiates between surfaces at two different scales with spatial periods above and below 200 microns (Bensmaïa \& Hollins, 2003, 2005; Bensmaïa, Hollins, \& Yau, 2005; Hollins,
Bensmaïa, \& Risner, 1998). For the relatively coarse textures above this point, a spatial model appears to hold. Johnson and associates modeled roughness perception as a multistage computation, beginning with a pressure map on the skin transduced by the SA I slowly adapting mechanoreceptors (see, e.g., Johnson \& Hsiao, 1994), and proceeding to sites in somatosensory cortex where inputs are combined into a measure of spatial variation. In contrast, the perception of roughness for fine surfaces with spatial periods of less than $\sim 200$ microns appears to be based on vibratory signals from the Pacinian Corpuscles (PCs). The importance of vibration at this level is indicated, for example, by vibrotactile effects of selective adaptation (Bensmaïa \& Hollins, 2003; Hollins, Bensmaïa, \& Washburn, 2001), as shown in Figure 4. Bensmaïa and Hollins (2005) found that direct measures of vibrations in the skin, as filtered by a PC model, predicted psychophysical differentiation of fine textures.

Thermal quality. The principal thermal property is the apparent warmth or coolness of a surface under contact, as mediated by the thermal receptors, which respond within a temperature range of $5^{\circ}-45^{\circ} \mathrm{C}$. The perceptions
A

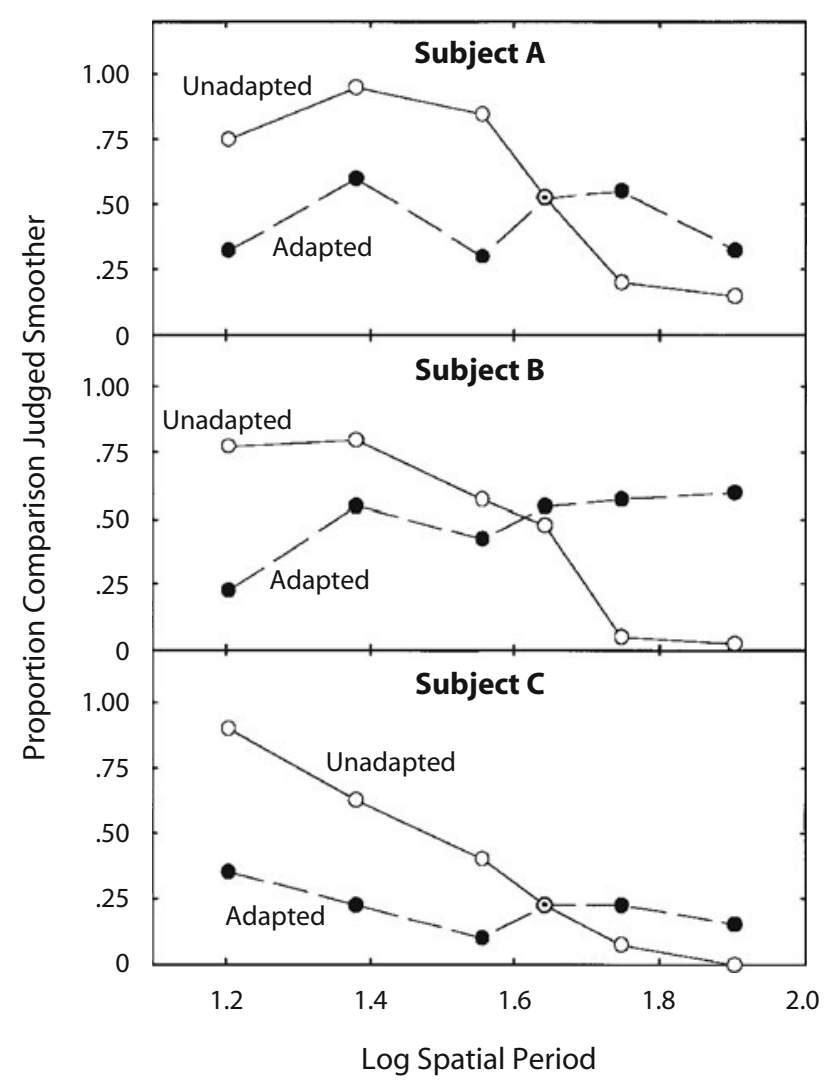

B

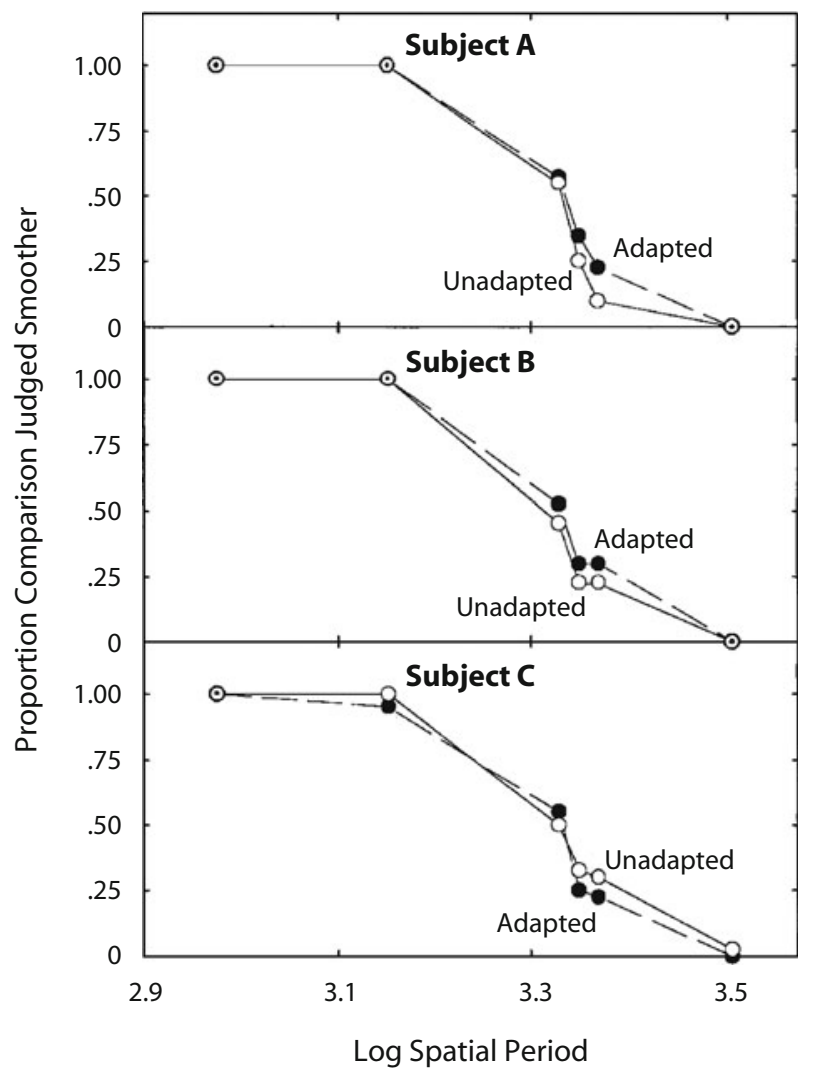

Figure 4. Effect of adapting the index finger to $100-\mathrm{Hz}$ vibration on discriminating fine (A) and coarse (B) surfaces. Proportion of trials on which the comparison surface was judged smoother than the standard surface (40 microns) as a function of log spatial period of the comparison surface. Note that discrimination in the unadapted state was eliminated for fine surfaces, but was unaffected for coarse surfaces. From "Vibrotactile Adaptation Impairs Discrimination of Fine, but Not Coarse, Textures," by M. Hollins, S. J. Bensmaïa, and S. Washburn, 2001, Somatosensory \& Motor Research, 18, p. 259. Copyright 2001 by Informa Healthcare. Reprinted with permission. 
of warmth and coolness arise from physical interactions between the skin and touched surface. Ordinarily, the temperature of the skin on the hand is within $25^{\circ}-36^{\circ} \mathrm{C}$ (Verrillo, Bolanowski, Checkosky, \& McGlone, 1998). Ambient temperatures are generally cooler than this range, which means that objects in the environment tend to conduct heat out of the skin at contact. Ho and Jones (2004, 2006) modeled the process of heat transfer by assuming that the finger pad and the surface were "semi-infinite" bodies. Under this model, the skin temperature changes at contact to an interface temperature determined by the initial skin and material temperatures and by the material itself-particularly its thermal conductivity, density, and specific heat. The difference between the initial skin temperature and the interface temperature - that is, how much the skin temperature changes at contact-is the essential signal for apparent temperature. This signal is transmitted by the thermoreceptor response to higher levels of processing that produce the percept of surface coolness (see also Jones \& Ho, 2008).

The importance of thermal quality as an object property is underscored by the finding that heating various materials so that they are all close to skin temperature, which eliminates thermal cues, impairs discrimination (Katz, 1925/1989). Materials can be differentiated to some extent solely by differences in their thermal properties. Bergmann Tiest and Kappers (2009) found that differences in thermal diffusivity - that is, the rate at which a material conducts heat away upon touch - predicted the ability to make material discriminations. The minimum diffusivity difference required to tell materials apart was found to be $43 \%$. A difference less than that value is what makes it difficult to tell copper from aluminum, whereas a greater difference makes it easy to tell glass from steel.

Compliance. The compliance of a touched object refers to its deformability under force. In a simple 1-D system, compliance can be expressed by Hooke's Law, as the relation of position to force. Srinivasan and LaMotte (1995) distinguished between objects with compliant versus rigid surfaces. The former show continuous indentation under pressure, whereas the latter deform the finger pad up to some critical point, then compress it. Detailed studies with robot-controlled force application versus active exploration and use of anesthetized versus normal fingertips have revealed distinct neural peripheral mechanisms for the two types of surface. Compliance of continuously deformable rubber specimens could be discriminated by the spatial pressure distribution over the contact region, as sensed by the cutaneous mechanoreceptors. Spring-loaded cells with rigid surfaces required kinesthetic as well as tactile cues for the spring constant to be discriminated. Figure 5 presents a schematic representation of the experimental apparatus.

Weight. The perceived weight of an object reflects its density and structure. To some extent, weight can be perceived when an object simply rests on a stationary hand; however, active exploration-particularly lifting and wielding the object - substantially enhances the ability to judge weight (Brodie \& Ross, 1984). Amazeen and Turvey (1996) proposed that the perceived weight of an ob-
A

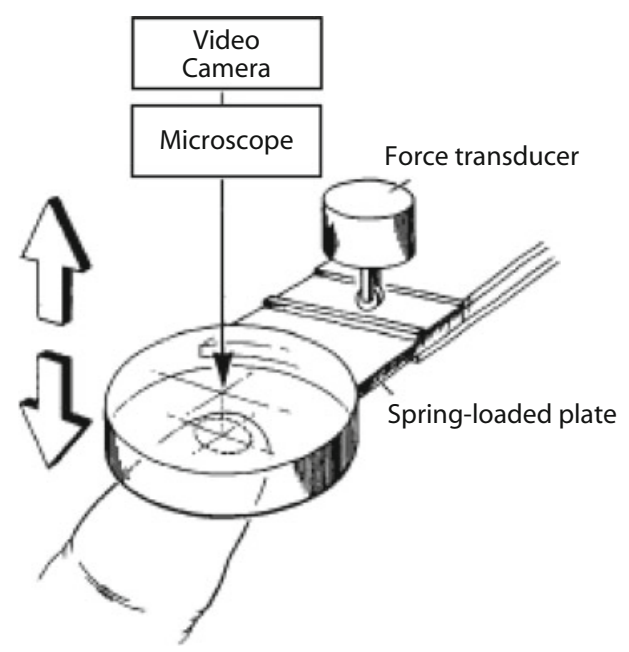

B

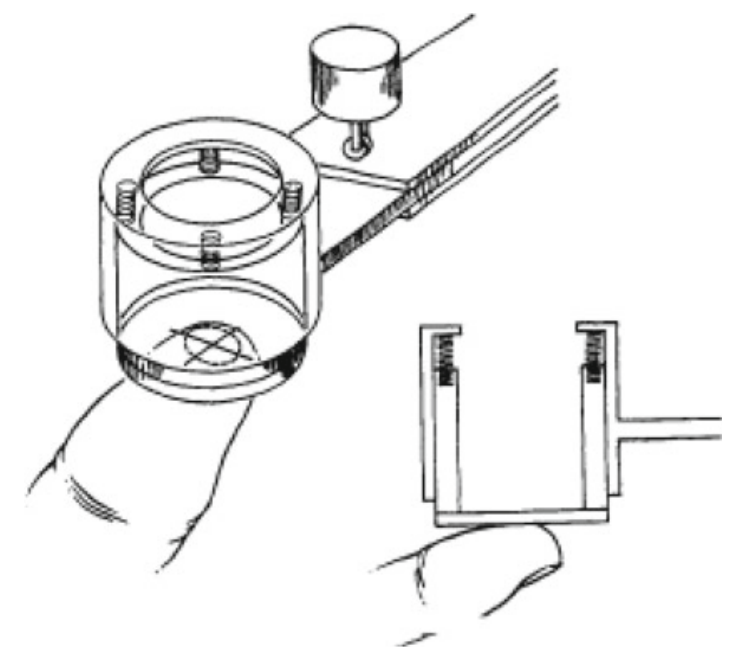

Figure 5. (A) Schematic of the experimental apparatus depicted with one of the transparent rubber stimuli that varied in compliance. The compliant stimulus was mounted on the spring-loaded plate, which protruded from a computer-controlled tactile stimulator. The plate contacted a force transducer used to measure contact forces between finger pad and stimulus under active- or passive-touch modes of stimulation. The contact regions were videotaped with a dissection microscope that was fitted with a video camera. (B) Schematic of the apparatus used to present deformable objects with planar rigid surfaces. A spring-loaded cell is shown mounted on the same spring-loaded plate (left) and in longitudinal section (right). Each stimulus consisted of two telescoping hollow cylinders with the internal cylinder able to move easily within the external cylinder. Four springs attached to the base plate of the external cylinder and linked to the internal cylinder determined the compliance of the stimulus. From "Tactual Discrimination of Softness," by M. A. Srinivasan and R. H. LaMotte, 1995, Journal of Neurophysiology, 73, p. 90. Copyright 1995 by the American Physiological Society. Reprinted with permission. 
ject wielded in the hand is determined by its resistance to the rotational forces of the limbs. Their model provides a physical measure of this property by means of the inertia tensor, a matrix of the moments and products of inertia. Because rotational forces are encountered as people lift and heft objects, these movements provide essential information for the judgment of weight. The model predicts that the distribution of an object's mass, as well as mass per se, will be critical to its weight when judged by wielding, in a manner specified by the changes in the inertia tensor.

A number of illusions related to weight perception have been demonstrated - for example, thermal/weight (Stevens, 1979), size/weight (Charpentier, 1891), and material/weight (Ellis \& Lederman, 1999) illusions, as well as the "golf-ball" illusion (Ellis \& Lederman, 1998), in which expert but not novice golfers perceive real golf balls to weigh less than practice golf balls engineered to be of the same mass. Undoubtedly, these variations in weight perception reflect a wide variety of mechanisms, ranging from low-level receptor responses all the way to high-level cognitive expectations.

Geometric properties. The size and shape of objects can be considered on two scales: objects that fit within the fingertip and thus reveal shape by skin indentation, and objects with contours that extend beyond fingertip scale, for which shape perception reflects the contribution of kinesthetic inputs. Of the various geometric properties, curvature has received particular attention. When the finger presses against a curved surface, responses of slowly adapting mechanoreceptors are directly mapped to the pressure gradient on the skin (Goodwin, Macefield, \& Bisley, 1997; LaMotte \& Srinivasan, 1993; Vierck, 1979). People can scale local curvature over a large range, from flat to $107 \mathrm{~m}^{-1}$; note that the curvature is inversely related to the radius of curvature (Louw, Kappers, \& Koenderink, 2000; Wheat \& Goodwin, 2001). Larger curves explored by touching multiple points, whether statically or dynamically, appear to be judged by the difference in local slope at different points of contact (Pont, 1997; Pont, Kappers, \& Koenderink, 1999).

The perception of geometric properties beyond fingertip scale is subject to a number of influences that undermine veridicality in systematic ways. For example, curvature perception depends on whether the curvature is convex or concave (van der Horst \& Kappers, 2008), the direction of movement over the surface (Davidson, 1972; Hunter, 1954), the position of the stimulus on the hand (Pont, Kappers, \& Koenderink, 1997, 1998), and on shape features other than the judged curvature (Vogels, Kappers, \& Koenderink, 1999). Haptic perception of linear extent is affected by the path length, curvature (Sanders \& Kappers, 2008), rate of exploration between endpoints (Armstrong \& Marks, 1999; Lederman, Klatzky, \& Barber, 1985), and other linear elements in the field (Heller \& Joyner, 1993).

Orientation. In keeping with vision, both vertical and horizontal lines are haptically perceived better than oblique lines (Lechelt, Eliuk, \& Tanne, 1976; Lechelt \& Verenka, 1980). Known as the oblique effect, the haptic version of this spatial anisotropy has been observed to

occur with both 2-D and 3-D stimuli and from at least 6 years of age through adulthood, without regard to visual status (sighted or blind). Gentaz and colleagues have argued (e.g., Gentaz \& Hatwell, 1995) that the haptic oblique effect is intrinsically dependent on the availability of kinesthetic gravitational cues produced during manual exploration by the hand-shoulder system, as well as on the additional memory constraints that sequential exploration commonly imposes on haptic processing. They suggest that the haptic oblique effect occurs at a relatively late stage of orientation processing, with the sensorimotor traces converted into a more abstract representation of spatial orientation. To this end, they suggest that the observer uses a frame of reference defined by the vertical and horizontal orientations. Whereas vertical and horizontal orientations can be encoded relative to one of these two axes, oblique lines must be encoded relative to both, thus requiring more calculations and possibly explaining, at least in part, the haptic orientation anisotropy (for further details, see Gentaz, Baud-Bovy, \& Luyat, 2008).

\section{Manual Exploration for Haptic Perception}

From the foregoing, it should be clear that haptic perception of surface and object properties is tightly bound

Lateral Motion (Texture)

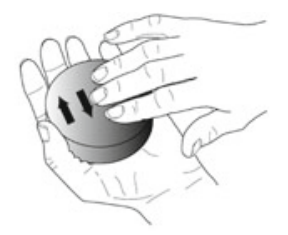

Pressure

(Hardness)

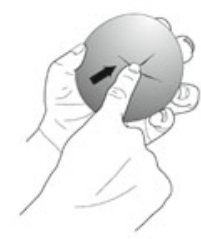

Static Contact (Temperature)

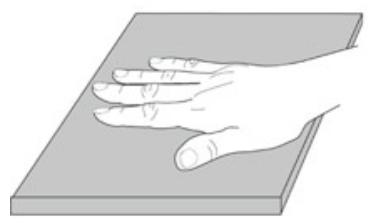

Figure 6. Depictions of six manual "exploratory procedures" and their associated object properties (in parentheses). From "Hand Movements: A Window Into Haptic Object Recognition," by S. J. Lederman and R. L. Klatzky, 1987, Cognitive Psychology, 19, p. 346. Copyright 1987 by Elsevier. Reprinted with permission. 
to the nature of contact (i.e., whether an object is pressed against the finger or explored over time, and how it is explored). Lederman and Klatzky (1987) have described a systematic relationship between exploration and object properties in the form of a set of exploratory procedures (EPs), of which the most intensively investigated are depicted in Figure 6. An EP is a stereotyped pattern of manual exploration observed when people are asked to learn about a particular object property during voluntary manual exploration without vision - and sometimes when vision is present.

For example, the EP associated with queries about apparent warmth or coolness is "static contact," which involves placing a large skin surface against an object without motion. Other EPs that have received most attention in the haptic research literature include "pressure" (associated with compliance), "unsupported holding" (weight), "enclosure" (volume; coarse shape), "lateral motion" (texture), and "contour following" (precise shape). The EP associated with a property during free exploration is also found to be optimal, in that it provides the most precise discrimination along the given dimension.

Exploratory procedures can be characterized not only by their stereotyped motor actions, but also by what those actions accomplish at neural and computational levels. In general, the EP associated with a property tends to optimize the activation of a set of associated neural receptors, thereby facilitating the computational mechanisms invoked by those receptors. For an example of this marriage among EP, neural output, and computation, consider roughness perception. The lateral motion EP, which moves the skin tangentially across a surface, enhances the responses of SA I mechanoreceptors (Johnson \& Lamb, 1981) and creates deep vibrations that activate the PCs (Bensmaïa \& Hollins, 2003). These two neural systems are thought to provide the input into the computation of perceived roughness at the macro- and microscale, respectively (Bensmaïa \& Hollins, 2005; D. T. Blake, Hsaio, \& Johnson, 1997).

\section{Costs and Benefits of Exploratory Procedures}

The various EPs have different costs and benefits (Klatzky \& Lederman, 1993; Lederman \& Klatzky, 1987). An EP has costs in terms of its execution time and its interference with other patterns of exploration that might occur at the same time; it has benefits if it provides incidental pickup of object properties for which it is not optimal. For example, the benefits of static contact are that it is quick to execute; it provides incidental information about texture, volume, and shape, as well as temperature; and it co-occurs with unsupported holding and enclosure. On the cost side, static contact cannot be coexecuted with dynamic EPs such as lateral motion or contour following. An overall analysis of EP costs and benefits led Lederman and Klatzky (1990) to predict that the most efficient way to process an object's properties was to grasp and lift it, thus instantiating the EPs of static contact, unsupported holding, and enclosure. This action would suffice to provide at least coarse information about material and structural properties. As predicted, when subjects were asked to verify whether a property described an object, their initial response tendency was to grasp and lift. Only subsequently did they use other EPs directed at the interrogated property.

\section{Haptic Perception of Multiattribute Objects}

We turn now to everyday objects, which tend to have multiple attributes such as weight, compliance, and shape. Klatzky and Lederman (2007) have argued that traditional models of visual object recognition (e.g., Biederman, 1987; Marr, 1982) are inappropriate for haptics because they generally emphasize the importance of spatially aligned edges, which the haptic system extracts poorly because of its relatively low spatial acuity (Weinstein, 1968). To establish fundamental principles of haptic object processing, it is instructive to consider the voluntary execution of haptic exploratory procedures, each associated with specific costs and benefits. As outlined next, two fundamental principles with respect to haptic processing and representation become evident.

When manual exploration of unfamiliar objects is temporally unconstrained, material properties are more perceptually salient than geometric properties. When the properties of objects are matched for perceptual discriminability, observers judging interobject similarity attend to material properties (texture, compliance, thermal, and weight) more when objects are encoded by touch alone than when objects are seen while being touched. Conversely, they weight geometric properties (2-D and 3-D shape and size) more when examining the same objects with vision present than by touch alone (e.g., Klatzky, Lederman, \& Reed, 1987; Lederman, Summers, \& Klatzky, 1996). The greater salience of material properties under haptic exploration presumably reflects the findings that a greater number of EPs convey information about material than geometry, and that EPs optimized for encoding material (cf. geometry) tend to be relatively precise and quick to execute.

Simultaneous execution of two or more exploratory procedures allows perceivers to integrate redundant properties about the identity of multiattribute objects. For example, Klatzky et al. (1987; see also Lederman et al., 1996) showed that object classification was faster when each object class was defined by redundant information along two object dimensions. The "redundancy gain" was shown to be governed by two factors: the extent to which single EPs deliver information about multiple object properties, and the potential of EPs to be coexecuted.

Relative contributions of spatial and temporal information in haptic object processing. The information used to recognize objects arises at different points during the time course of manual exploration and has multiple spatial components. It is possible to assess the relative contribution of different spatial and temporal cues by constraining haptic exploration, thereby eliminating certain information sources. The resulting decrement in performance signals the contribution of the missing information. In this section, we consider three examples of this restricted-exploration approach. 
Contributions of cutaneous array sensing assessed by eliminating spatially distributed force feedback. What happens when the spatially distributed deformation patterns normally available to fingertip receptors are eliminated? This commonly occurs, for example, when people use an intermediate tool (e.g., a pencil) to explore an object. In this case, haptic perception is considered remote or indirect, and the skin receives most of its information in the form of vibrations. In one study that modeled this situation (Lederman \& Klatzky, 1999), observers performed a battery of simple sensory tests and more complex perceptual tests with and without a rigid finger sheath that covered the palmar surface of the index finger from the extreme tip to the most distal finger joint. Not surprisingly, while using the rigid sheath participants showed no deficit when detecting vibrations. They were moderately successful at perceptually differentiating roughness. In marked contrast, they could not resolve the orientation of raised bars delivered to the fingertip, and were less successful locating the presence of a 3-D artificial "lump" embedded in artificial "tissue."

Contributions of kinesthetic feedback assessed by spatial constraints. Researchers have also investigated the consequences of depriving observers of normally available kinesthetic spatial cues that extend beyond the size of the fingertip (Klatzky, Loomis, Lederman, Wake, \& Fujita, 1993; Lederman \& Klatzky, 2004). Observers were confined to using one finger rather than five, rigidly splinted finger(s), fingertip(s) covered with a thick but compliant material, and/or a rigid probe or finger cover. These constraints mainly differed in the extent to which the observer was capable of properly tracing the object's contours with a contour-following EP and/or in molding the fingers to the contours with an enclosure EP. The various constraints impaired haptic object recognition to differing degrees in terms of accuracy and/or response time.

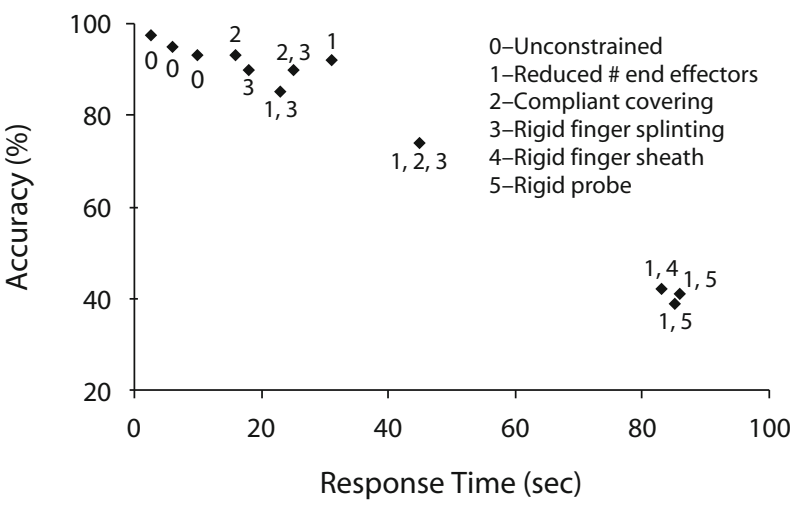

Figure 7. Recognition accuracy (\%) as a function of response time (sec) for different constraint conditions involving manual exploration, alone and in various combinations. The constraint conditions are shown both by name and by corresponding number in the legend. The data are derived from experimental conditions in Klatzky, Loomis, Lederman, Wake, and Fujita (1993) and Lederman and Klatzky (2004). The comma indicates multiple simultaneous constraints. Copyright 2004 by the Psychonomic Society, Inc.
Moreover, as shown in Figure 7, the greater the number of end-effector constraints, the more performance declined.

Contribution of extended exploration assessed by restricting contact duration. We have just described some of the significant ways in which restricting the nature and amount of spatial information, both cutaneous and kinesthetic, can impair haptic object processing. Limiting the duration of manual exploration has its own important consequences, particularly because material properties are available for haptic processing earlier than geometric ones are. In a series of experiments that employed a tactual version of the visual search paradigm used by Treisman and colleagues (e.g., Treisman \& Gelade, 1980), Lederman and Klatzky (1997) showed that when delivered to the static fingers of both hands, material features (rough vs. smooth, soft vs. hard, cool vs. warm) and edges (present vs. absent) are all available for further processing relatively earlier than geometric information (e.g., bar orientation, curvature, 3-D slant, relative position), as indicated by the essentially flat search functions (response time as a function of number of items in the display). Similar "pop-out" effects for texture have since been confirmed using active touch (Plaisier, Bergmann Tiest, \& Kappers, 2008). In addition, Overvliet, Smeets, and Brenner (2007) have presented an elegant model of haptic search that successfully predicts serial search for geometric features (shape, i.e., cross target vs. circle distractors; orientation, i.e., vertical target vs. horizontal distractors) and parallel processing for the simple detection of a line target versus blank distractors.

Other research (Klatzky \& Lederman, 1995) suggests that a brief "haptic glance" lasting about $200 \mathrm{msec}$ is sometimes sufficient for haptic identification of familiar objects with highly diagnostic features, whether they are geometric (local shape) or material. Finally, the duration of manual exploration has been shown to influence haptic processing in terms of the distinction between featural and global processing of object structure. When haptically evaluating the relative similarity of pairs of geometric objects fairly alike in their global shape, observers initially focus more on local shape features than on global structure; with continued manual exploration, however, observers focus more on the global shape at the expense of the local features. No such switch in focus occurs for objects dissimilar in their global shapes and without notable local features (Lakatos \& Marks, 1999, as depicted in Figure 8; see also Berger \& Hatwell, 1993).

\section{The "Where" System and Haptic Space Perception}

Like its counterpart in vision, the "where" system for touch provides a description of the layout of points, surfaces, and objects in the world. Touch differs from vision, however, in that localization can be referred to the sensory organ itself - the skin - as well as to the environment. Therefore, we consider two types of haptic spatial localization-determining where on the body a stimulus is being applied, and determining where in the space external to the body a stimulus is being touched. 


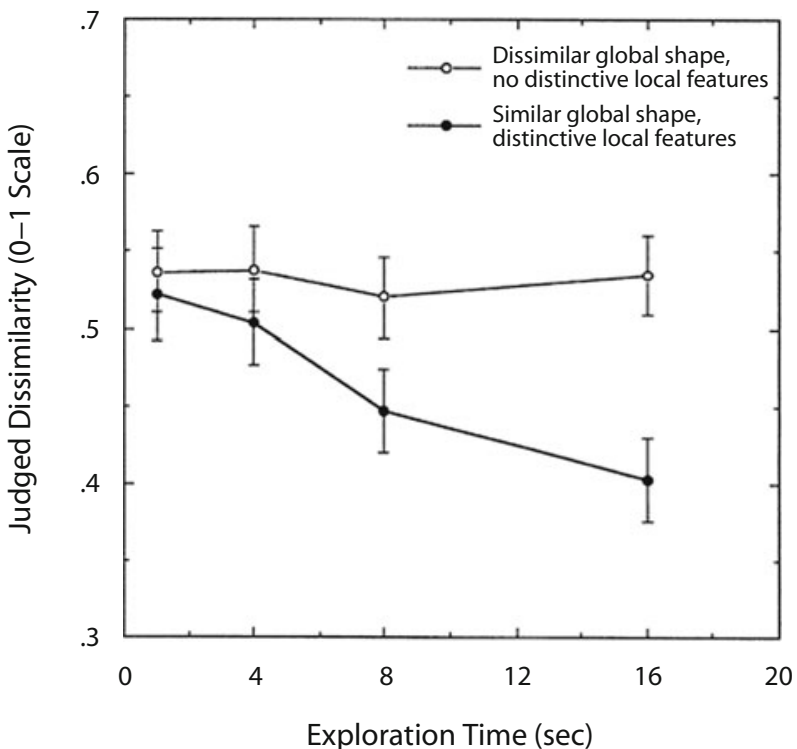

Figure 8. Rated dissimilarity values ( \pm standard error) as a function of exploration duration (sec) for two sets of stimuli: object pairs differing in their global features and with no distinctive local features (open circles), and object pairs with similar global shape and distinctive local features (filled circles). Copyright 1999 by the Psychonomic Society, Inc.

\section{Frames of Reference for \\ Haptic Spatial Localization}

Considering touch as a system for spatial localization immediately raises a fundamental question: What is the frame of reference within which localization occurs? In general, a frame of reference defines a coordinate system, or a set of parameters, for localizing points (Klatzky, 1998). The coordinate system may be Cartesian or polar, and its origin may be the perceiver's body or some body part, or defined in terms of landmarks external to the individual. Multiple frames of reference are generally simultaneously available, and performance of a given task may use a single frame or take into account multiple frames.

Both types of spatial processing mentioned above, determining the site on the body contacted and localizing within external space, are grounded in contact between the skin and an external object; however, the frames of reference are obviously different. Localizing points on the body uses a local frame of reference, such as the axes of the fingertip. Haptic localization of points in external space often refers to an "egocentric" frame of reference, where distances and directions are specified relative to the actor; the origin of this frame is called the egocenter. In contrast, a reference frame parameterized by landmarks and axes external to the observer is called an "allocentric" frame.

\section{Bodily Localization}

A significant issue for touch science involves understanding how people localize discrete contacts on their own bodies: Where was I touched? Research has shown that localizing the sites of body contact is affected by a number of factors, among them the following.
Spatial resolving capacity of the skin. The precision with which humans can localize bodily contact is first and foremost affected by the spatial resolving capacity of the skin, which in turn is influenced by various factors, including body site, age, and visual experience. The reader should refer back to the previous section (The "What" System), where we address this topic in some detail.

Spatial mislocalizations on the skin. Research has shown that space-time interactions produce systematic mislocalizations of the location of body contact. Like both vision and audition, touch is also subject to the wellknown "tau" illusion in which the apparent distance separating three equally spaced contacts delivered sequentially to the forearm depends on the intervening temporal intervals (Helson \& King, 1931). If the temporal interval between the first and second contacts is shorter (longer) than that between the second and third contacts, the corresponding distance on the forearm between the first two contacts is perceived to be shorter (longer) than between the second and third contacts.

A second example in which bodily contact is mislocalized relates to illusory movement known as phi (or more accurately, beta) movement. This form of apparent motion is most familiar in the vision literature, and is easily produced by showing two spatially separated lights that flash on and off in succession. Observers perceive a single light moving smoothly between the two stimulus positions when the complex spatial and temporal interactions follow Korte's laws (see Boring, 1942). The best stimulus for creating a tactile variant of smooth apparent motion on the skin is one that is periodic-for example, producing vibrotactile bursts of $150 \mathrm{~Hz}$ (Sherrick \& Rogers, 1966).

Yet another form of mislocalization is known as sensory saltation, or more familiarly, the "rabbit" illusion (e.g., Flach \& Haggard, 2006; Geldard \& Sherrick, 1972). For example, consider a series of 15 brief taps delivered in equal temporal succession to 3 contactor sites equally spaced along the forearm. Five taps are delivered to the 1 st contactor site, followed by 5 to the 2 nd contactor site, and finally 5 more to the 3 rd contactor site. Observers report an illusory sweeping movement of discrete taps that occur in a linear sequence along the forearm at the real contactor sites and at illusory ones in between. Some have likened their impressions to the feeling of a tiny rabbit hopping up the arm. Although initially discovered on the skin, this form of spatial mislocalization has since been documented in a number of the other sensory systemsvisual, auditory, and even thermal systems (Geldard, 1975; Trojan et al., 2006). Goldreich (2007) has offered a Bayesian account of the cutaneous rabbit, as well as other spatiotemporal tactile illusions. Neural concomitants of the effect have been shown to occur in primary somatosensory cortex (Blankenburg, Ruff, Deichmann, Rees, \& Driver, 2006).

Failing to detect changes in spatial pattern on the skin. There is now a substantial literature documenting change blindness, a striking inability to detect large changes to a visual or auditory scene (vision-e.g., 
Rensink, O’Regan, \& Clark, 1997; audition-e.g., Vitevitch, 2003). Most recently, a tactile analogue of change blindness has also been reported (Gallace, Auvray, Tan, \& Spence, 2006), whereby observers demonstrate an inability to perceive spatial changes (element addition or deletion) to simple tactile patterns. These tactile spatial events were presented in sequence, along with a vibrotactile mask (tactile "mudsplash") that coincided with the start of the spatial change.

\section{Localization in Space External to the Body}

Here we consider how people localize points in space external to the body that they encounter during haptic exploration without vision. Research on haptic space perception has produced a number of intriguing phenomena, but as yet no encompassing theory (see, e.g., Millar, 1976, 1994). A salient point emerging from this literature is that reports of haptically perceived spatial layout are subject to a variety of distorting influences, particularly from the nature of exploration. An interesting contrast is found between people's ability to return to a previously touched location in space and their ability to report where that location is in space (Klatzky \& Lederman, 2003). The former can be performed on the basis of a motor memory, whereas the latter calls for a representation of space grounded in haptic processing. Construction and use of this representation appear to produce the errors that were observed.

In some cases, systematic error trends appear to result because haptic perceivers have available a number of potential reference frames, which can simultaneously contribute to the perceptual outcome. Haptic spatial localization may refer either to a coordinate system centered on the body, thus constituting an egocentric frame of reference, or to an allocentric frame of reference, such as would be defined by the edges of a table. As noted above, when we consider where objects are in egocentric space (i.e., relative to the body), we invoke the concept of an egocenter, a point on or within the body that serves as the origin for the operative reference frame. In vision, the egocenter has been localized between the eyes (Howard \& Templeton, 1966). In touch, the frame of reference has been found to vary with the task and with the posture of the individual who is performing it. Shimono, Higashiyama, and Tam (2001) tested for the egocenter by asking people to align a set of objects at different distances from their bodies so that they pointed to themselves (see Figure 9). Different angles of alignment were employed, and the point of intersection was used to determine the convergent egocenter. The location of the convergence was not fixed, but rather depended on both the object distance and the hand used to perform the manual adjustments. Such variability of the haptic egocenter has been broadly demonstrated.

In addition to the multiplicity of egocentric reference frames that can be tapped, haptic spatial localization may use allocentric frames, and here too there are multiple candidates. Observers may localize objects relative to intrinsic environmental axes (e.g., the edge of a tabletop), or they may use a subset of objects to define a frame for localizing others. Some haptic spatial tasks seem to call into play multiple frames of reference, particularly when objects must be localized within an allocentric frame.

Kappers and colleagues demonstrated the use of multiple frames when subjects were required to orient rods relative to each another. The task was to orient an adjustable bar so that it was parallel to the angle of a reference bar located on the same plane. Figure 10A shows an arrangement of a pair of rods aligned by a hypothetical subject so as to appear "parallel" using the standard setup for Kappers's studies. Note that the bar to the right of the subject's midline would require a clockwise deviation from the reference angle to be perceived as parallel, and vice versa for
A

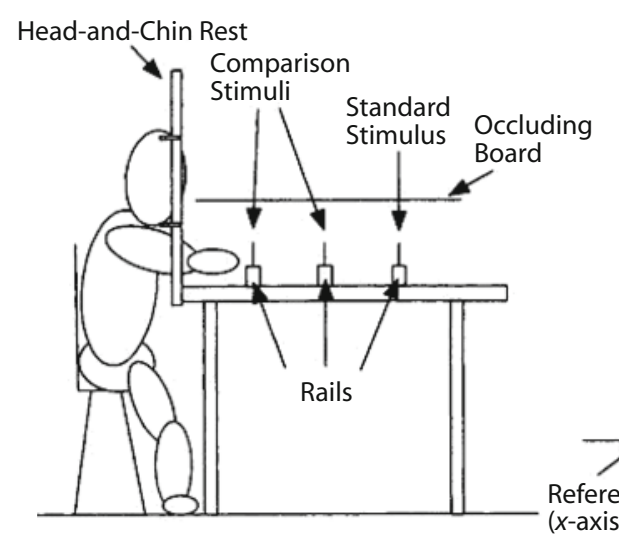

B

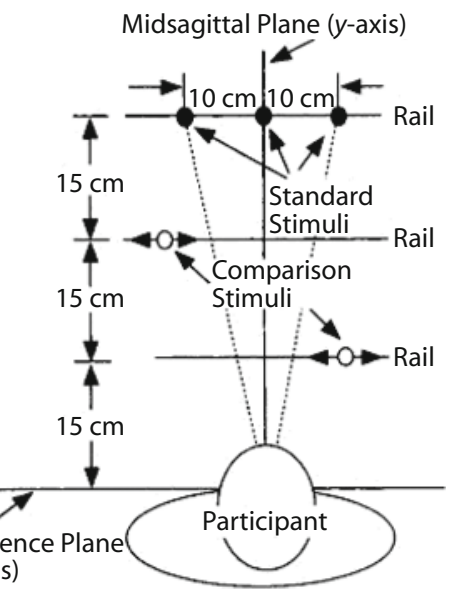

Figure 9. (A) Schematic side view and (B) schematic view of the apparatus and stimulus configuration. Note that in the experiment, only one comparison stimulus, at a distance of either 15 or $30 \mathrm{~cm}$, was used in any given trial. From "Location of the Egocenter in Kinesthetic Space," by K. Shimono, A. Higashiyama, and W. J. Tam, 2001, Journal of Experimental Psychology: Human Perception \& Performance, 27, p. 849. Copyright 2001 by the American Psychological Association. 
A

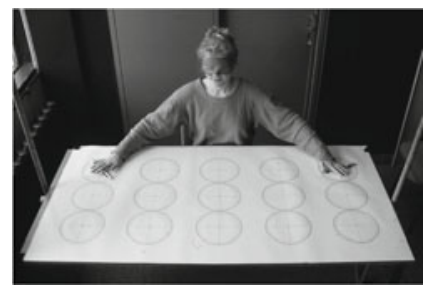

C

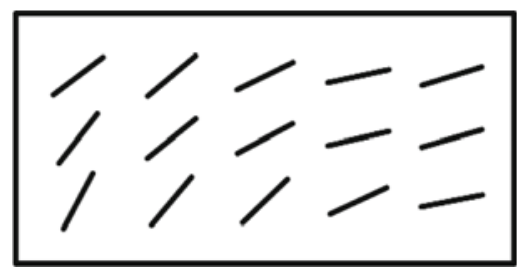

B

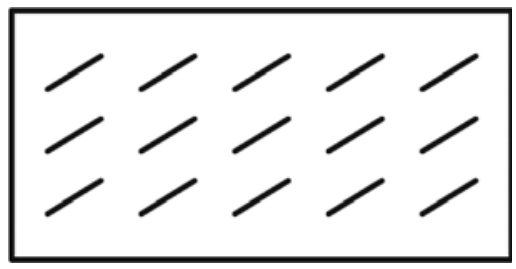

D

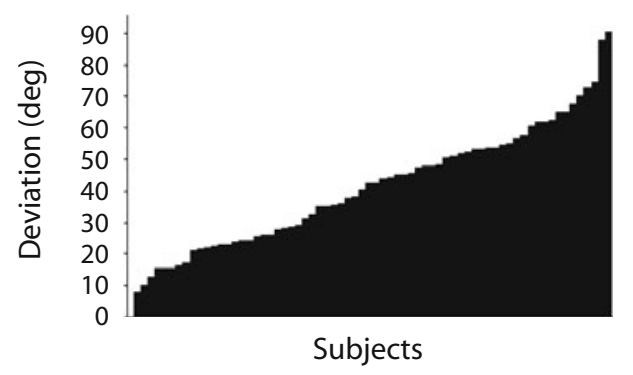

Figure 10. (A) Standard setup for experiments on the haptic perception of horizontal tabletop space. According to empirical data, the two bars in this figure may be perceived as being close to haptically "parallel." (B) A set of objectively parallel lines that maximally overlap with the measurements in panel C; (C) "Perceived parallel" settings to match the objectively parallel bars in panel B by one subject using her right hand. Figures $10 \mathrm{~A}, 10 \mathrm{~B}$, and $10 \mathrm{C}$ are from "Haptic Spatial Processing: Allocentric and Egocentric Reference Frames," by A. M. L. Kappers, 2007, Canadian Journal of Experimental Psychology, 61, pp. 209, 210. Copyright 2007 by the Canadian Psychological Association. Reprinted with permission. (D) Histogram of the distribution of deviations, each bar representing that of an individual subject. From "Large Systematic Deviations in a Bimanual Parallelity Task: Further Analysis of Contributing Factors," by A. M. L. Kappers, 2003, Acta Psychologica, 114, p. 132. Copyright 2003 by Elsevier. Reprinted with permission.

the bar to the left of her body midline. Figure 10B shows a full set of objectively parallel bars. Figure 10C shows the adjustments made by one subject with her right hand to perceptually match the parallelism of the rods presented in Figure 10B. Figure 10D shows the wide range $\left(8^{\circ}-91^{\circ}\right)$ of individual subject errors observed in one study (Kappers, 2003), depending on the position of the adjustable bar relative to the reference bar. A model proposed to account for these results suggested that subjects used two competing frames of reference, one centered on the body (most probably the hand) and the other anchored to external space. The relative weightings of these frames differed across subjects.

A fundamental question about haptic space perception is whether the distance metric is uniform across space, regardless of distance magnitude and direction. This would constitute isotropy. A number of illusions have shown that haptic space is anisotropic. In the radial/tangential illusion, for example, linear extents felt along a radius toward and away from the body are perceived as longer than the same extents felt along a tangent to that radius (e.g., Cheng, 1968; Marchetti \& Lederman, 1983). Another case is the horizontal-vertical illusion: When people feel T- or L-shaped raised stimuli presented on the horizontal plane, vertical lines are overestimated relative to length-matched horizontal components (e.g., Burtt, 1917). The magnitude of these anisotropies has been found to depend on the patterns of movement by which the extents are explored (Heller, Calcaterra, Burson, \& Green, 1997; Wong, 1977).

\section{Other Significant Issues}

\section{Vision-Touch Interactions}

Vision-touch integration. When we pick up an apple and feel its smooth, rounded contours, we also see it, smell it, and hear the slide of our fingers along its surface. Intersensory interactions have long been of interest to perception researchers. Not surprisingly, there has been considerable research on interactions between haptic perception and other sensory modalities. Perhaps the most general question is: How are inputs from multiple modalities about a common physical event combined? A number of methodologies have been used to answer this question, usually by comparing data from unimodal with that of bimodal or multimodal conditions.

Multimodal interactions can be characterized by estimating the relative weight given to each of the input modalities in the conjoint percept. Simple additive models have been used to fit a bimodal response function as a weighted average of the unimodal conditions (Anderson, 1974). In another manipulation known as intersensory conflict, the perceiver is presented with discrepant bimodal information about a single physical entity. The response (e.g., matching; 

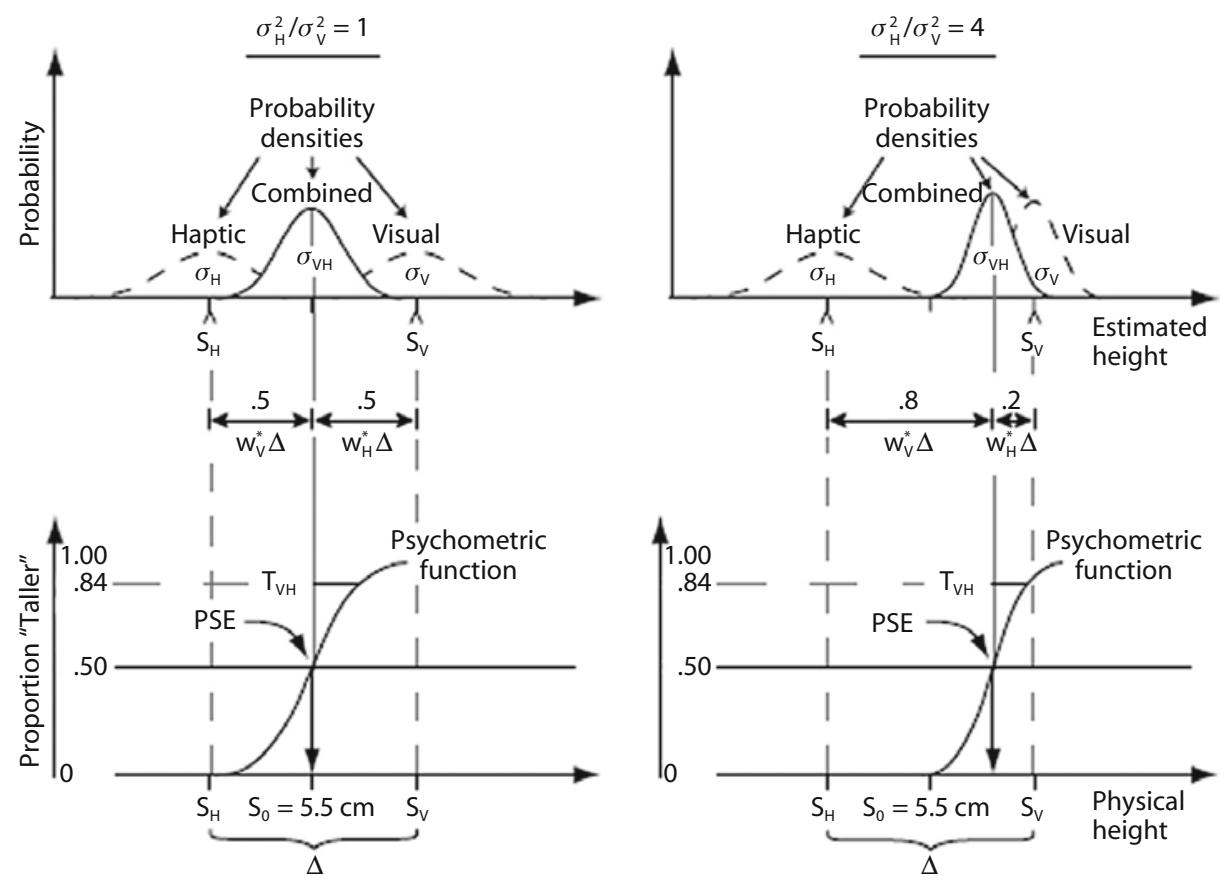

Figure 11. Maximum likelihood estimate integration: two hypothetical situations. Visually and haptically specified heights differ by $\Delta$. Dashed Gaussians in the top panels represent probability densities of the (unbiased) estimated height from visual and haptic assessment, and solid Gaussians represent probability densities for the combined estimate. On the left, the visual and haptic variances are equal $\left(\sigma_{\mathrm{H}}^{2} / \sigma_{\mathrm{V}}^{2}=1\right)$ and both their weights are .5 . The mean of the combined probability density is equal to the mean of the visual and haptic densities and the variance is reduced by half. On the right, the haptic variance is four times the visual variance $\left(\sigma_{\mathrm{H}}^{2} / \sigma_{\mathrm{V}}^{2}=4\right)$. The visual weight $\left(\mathrm{w}_{\mathrm{v}}\right)$ is then .8 and the haptic weight $\left(w_{H}\right)$ is .2 . Thus, the combined probability density is shifted toward the visual estimate. From "Humans Integrate Visual and Haptic Information in a Statistically Optimal Fashion,” by M. O. Ernst and M. S. Banks, 2002, Nature, 415, p. 430. Copyright 2002 by Macmillan. Reprinted with permission.

forced choice comparison) is used to infer the contribution of each modality to the bimodal percept. A version of this paradigm, based on maximum-likelihood estimate (MLE) models (Ernst \& Banks, 2002), constructs psychophysical functions from two-alternative forced choice tasks, where the function is a sigmoid describing the change from one choice to the other across a modulation of the stimulus (see Figure 11). Unimodal data are used to measure the mean and reliability (inversely related to variance) of each sensory input. A bimodal condition with discrepant stimuli is then tested to determine whether observers weight the sensory inputs in inverse relation to their reliability, as predicted by the MLE model.

Research on intersensory interactions of haptic inputs with other modalities has predominately focused on how vision is combined with touch, although haptic/auditory interactions have also been studied (e.g., Jousmäki \& Hari, 1998; Rock \& Victor, 1964; Spence, Nicholls, \& Driver, 2001). In keeping with modality specializations outlined above, the relative weighting of vision in relation to touch is greater when geometric properties are being judged than when material properties are tested. For example, vision/haptic interactions have been found to weight vision relatively more strongly when texture is defined spatially, but for the weight to shift toward touch when texture is defined intensively, in terms of roughness (Lederman, Thorne, \& Jones, 1986). The prediction of the MLE approach - namely, that the modality weights reflect their relative reliabilities - has been confirmed, for example, with respect to visual/haptic edges (Ernst \& Banks, 2002) (see Figure 12 for a depiction of the experimental setup). However, the MLE model breaks down when the inputs do not appear to originate from the same physical source location (Helbig \& Ernst, 2007).

Higher level vision/touch interactions. Up to this point, we have dealt with situations where vision and haptic inputs provide information, potentially discrepant, about a single property of an object or event. Intersensory interactions extend as well to situations where vision and touch provide information about different objects, calling for allocation of attention or interobject interaction. In the domain of cross-modal attention, Cinel, Humphreys, and Poli (2002) found an analogue to illusory conjunctions, first demonstrated with respect to intramodal visual interactions such as confusions between shape and color (Treisman, Sykes, \& Gelade, 1977). Subjects in the Cinel et al. study touched an unseen textured bar while viewing two objects, each a shape (e.g., a square) composed of textured material (carpet, fur, beans, or brick). They reported the horizontal-vertical orientation of the touched 


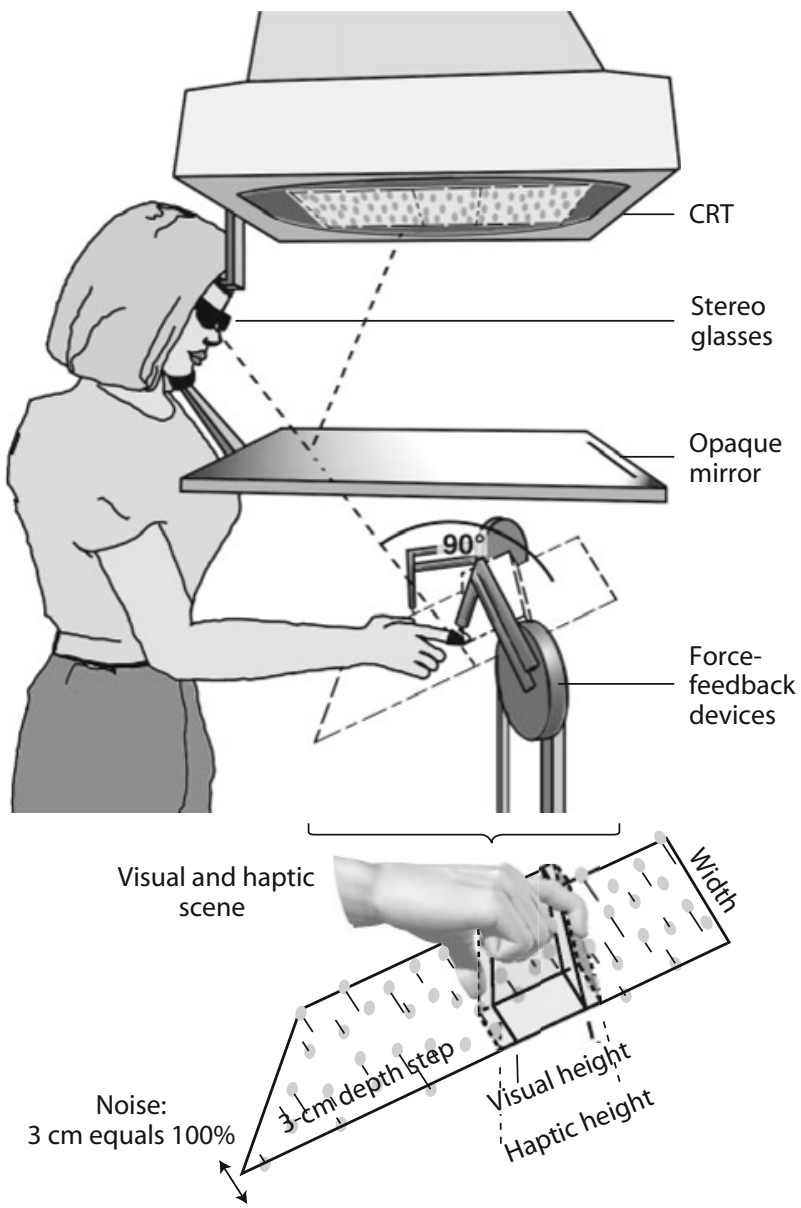

Figure 12. Apparatus and virtual stimulus. Observers viewed the reflection of the visual block stimulus. Liquid-crystal shutter glasses were used to present binocular disparity, producing stereo vision; noise was implemented by reducing the stereo cues. The haptic stimulus was presented to the unseen right hand via two force-feedback devices, one each for the index finger and thumb. From "Humans Integrate Visual and Haptic Information in a Statistically Optimal Fashion," by M. O. Ernst and M. S. Banks, 2002, Nature, 415, p. 431. Copyright 2002 by Macmillan. Reprinted with permission.

bar and then which objects had been visually presented. There were frequent intermodal conjunction errors, in which the texture of the touched bar was attributed to a reported visual object.

Intermodal interactions extend even to social attribution and intention. Williams and Bargh (2008) found that subjects who briefly held a cup of hot coffee subsequently perceived a companion to be more generous and caring than did those who held an iced coffee. A similar manipulation with a hot therapeutic pad increased the subject's tendency to give a gift to a friend rather than to retain it. The authors conjectured that insular cortex might mediate the linkage between thermal perception and the attribution of personal warmth or coolness.

\section{Affective Touch}

Up to this point, we have addressed the sense of touch in terms of crucial issues that pertain to the haptic discrim- ination, perception, and recognition of external objects and their properties. In keeping with recent trends in other fields, the science of touch has also begun to focus on understanding affective aspects of this modality, such as pleasantness and emotional expression. For example, neuroscientists and psychophysicists have recently hypothesized that the rewarding, emotional aspects of touch may be subserved by a class of unmyelinated peripheral nerve fibers known as CT (or C tactile) afferents that are found in hairy, but not glabrous (hairless), skin (Löken, Wessberg, Morrison, McGlone, \& Olausson, 2009; McGlone, Vallbo, Olausson, Löken, \& Wessberg, 2007; Olausson et al., 2002).

Researchers have also recently shown that it is possible to tactually communicate culturally universal human emotions via contact on the arm (Hertenstein, Keltner, App, Bulleit, \& Jaskolka, 2006) and by haptically exploring emotional expressions depicted on live faces, 3-D facemasks, and even 2-D raised-line drawings (Lederman, Kilgour, Kitada, Klatzky, \& Hamilton, 2007; Lederman et al., 2008).

\section{Visual Mediation Versus Multisensory Processing During Tactile/Haptic Perception}

A somewhat controversial proposal that pertains particularly to interactions between vision and touch is whether touch may serve as an input channel for subsequent visual processing. This idea has been reinforced by evidence obtained with functional-imaging techniques - namely, that the visual cortex is generally involved in normal tactile perception by both sighted and blind observers (e.g., Sathian \& Lacey, 2007). More specifically, judgments of the layout of touched objects and of stimulus motion on the skin have been found to activate areas in the dorsal visual pathway (macrospatial, Kitada et al., 2006; Sathian, Zangaladze, Hoffman, \& Grafton, 1997; Stoesz et al., 2003; motion, R. Blake, Sobel, \& James, 2004; Hagen, Zald, Thornton, \& Pardo, 2002). However, haptic shape perception of 3-D objects activates the ventral visual pathway (e.g., Amedi, Jacobson, Hendler, Malach, \& Zohary, 2002; Amedi, Malach, Hendler, Peled, \& Zohary, 2001; Deibert, Kraut, Kremen, \& Hart, 1999; James et al., 2002; James, Servos, Kilgour, Huh, \& Lederman, 2006; Kitada, Johnsrude, Kochiyama, \& Lederman, 2009; Malach et al., 1995; Pietrini et al., 2004; Reed, Shoham, \& Halgren, 2004; Stoeckel et al., 2003; Zhang, Weisser, Stilla, Prather, \& Sathian, 2004).

What remains unclear is the nature of visual processing of tactile inputs that gives rise to such visual cortical involvement. Visual involvement could include (1) knowledge-directed processes (e.g., anticipatory visual imagery, visual memory) that may assist or mediate tactual performance; (2) stimulus-directed activation of visual cortical areas by tactual inputs, implying that these so-called "visual" areas are actually "multisensory"; or (3) both knowledge-driven and stimulus-driven processes (Lacey, Campbell, \& Sathian, 2007; Sathian \& Lacey, 2008).

Evidence consistent with the use of visual imagery during passive tactile and active haptic object processing has 


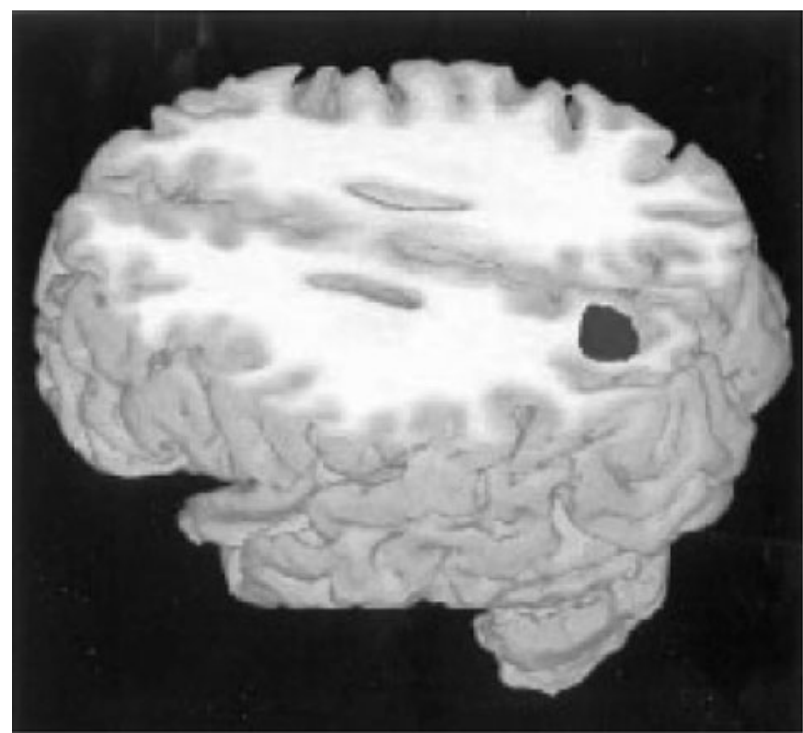

Figure 13. The MRI of a subject showing parieto-occipital activation resulting from selective attention to grating orientation (vs. relative size of grating ridges and grooves); 3-D rendered image with the top of the brain cut away to reveal its location. The display threshold is $p<.001$ ( $t>3.31$; uncorrected for multiple comparisons). From "Feeling With the Mind's Eye," by K. Sathian, A. Zangaladze, J. M. Hoffman, and S. T. Grafton, 1997, NeuroReport, 8, p. 3879. Copyright 1997 by Lippincott Williams \& Wilkins. Reprinted with permission.

been obtained in several tasks involving the tactile perception of grating orientation (e.g., Sathian \& Zangaladaze, 2001; Sathian et al., 1997 [see Figure 13]; Zangaladze, Epstein, Grafton, \& Sathian, 1999; Zhang et al., 2004) and the haptic recognition of common objects depicted in 2-D raised-outline drawings (Lederman, Klatzky, Chataway, \& Summers, 1990). However, visual imagery is by no means necessary, as shown in an fMRI study that compared haptic, visual, and visually imaged identification of specific exemplars of 3-D plaster casts of different body parts (Kitada et al., 2009). Auxiliary data from three complementary measures of the contribution of visual imagery provided evidence that, at best, visual mediation could explain only a relatively small part of the category-specific signal increase obtained with haptically presented body parts. Nonsignificant, or significant but very low, correlations were obtained between activation patterns produced by conditions in which subjects haptically explored versus visually imagined the objects, between the activation patterns of subjects who described themselves as using visual imagery in the haptic condition and those who did not, and between scores on the VVIQ questionnaire (Marks, 1973), which measures the vividness of subjects' visual imaging abilities, and activation during haptic object identification. As Kosslyn and Thompson (1993) and Lacey et al. (2007) have noted, visual imagery is a highly complex process that consists of multiple components (e.g., image generation, maintenance, inspection, and transformation). Greater understanding of visual imagery, together with a more extensive battery of evaluation tasks, is much needed to clarify the contribution(s) of visual imagery to tactile/haptic processing of familiar and unfamiliar raised 2-D patterns and 3-D objects.

Neural imaging studies also provide some evidence for the activation of shared neural networks by the presentation of objects either haptically or visually. For example, in the study by Kitada et al. (2009), greater modalityindependent activation of the fusiform face area within the fusiform gyrus and of the extrastriate body area in the lateral occipital cortex was found when subjects identified faces or other body parts (hands, feet), respectively, as compared with nonbiological control objects (bottles).

Lacey et al. (2007) and Sathian and Lacey (2008) have now examined a large number of studies (including, but not limited to, most in this section) with respect to whether visual mediation and/or multisensory processing is used during tactile/haptic perception. Overall, they conclude that the current evidence collectively points to the creation of a multisensory spatial representation that may be flexibly accessed via either knowledge-driven or stimulus-driven processes. They qualify their conclusion by further noting that comparisons between unimodal modality-specific representations cannot be completely ruled out, and that unimodal representations may also be present. Owing to the brevity of this tutorial, we refer interested readers to the two reviews above for specific details regarding the evidence used by Lacey and Sathian to support their conclusions.

\section{Plasticity}

We briefly mention that the malleability of sensory representation in the brain must be considered one of the striking developments in perception over the last two decades or so. Pioneering work in this area involved the sense of touch (for a review, see Buonomano \& Merzenich, 1998). Merzenich, Kaas, Wall, Sur, and Lin (1978) conducted an early study in which the median nerve of a monkey was transected, resulting in the cessation of inputs from portions of the thumb, index, and middle finger to two somatosensory cortical areas. In just a few weeks, representations of the bordering skin areas were found in these areas. These original studies have been followed by a large body of work on functional plasticity and underlying mechanisms.

For example, Pascual-Leone and Hamilton (2001) reported a study in which normal, sighted subjects were blindfolded for a period of five days, over which serial fMRIs were performed. As the interval progressed, the striate and peristriate cortex was activated progressively more during tactile stimulation. On Day 1, the contralateral somatosensory cortex, but not the occipital cortex, was activated. From Day 2 through Day 5, BOLD activation in the somatosensory cortex decreased as it increased within the "visual" occipital areas. When the blindfold was removed and subjects were permitted to see for a period of 12 to $24 \mathrm{~h}$, all changes produced during the blindfolding interval were eliminated. Rapid reversibility of this phenomenon, as demonstrated by Merabet et al. (2008), suggests that the effect of visual deprivation may release inhibition that would otherwise be present. 


\section{Applications}

In the last 10 years or so, there has been a veritable explosion in the multidisciplinary study of haptics by psychophysicists and other experimental psychologists, mechanical and electrical engineers, and computer scientists. The overall goal in this field is to develop effective tactile, haptic, and multisensory interfaces for use in a wide range of application domains involving different teleoperational and virtual environments. Exciting examples include, but are not limited to, providing tactile and/or haptic cues for minimally invasive surgery, e-commerce, recreational games, electromechanical graphics displays for the blind, and multisensory environments for virtual novice surgeons. One of the most recent and potentially pervasive applications includes adding haptics to mobile phones, PDAs, and large-scale displays.

In concluding, it is important to recognize that basic and applied research on haptics mutually influence each other in valuable ways. The results of fundamental scientific research on human haptics offer valuable guides and statistical tools for designing and evaluating the effectiveness of haptic interfaces, sensory substitution systems, and sensorized prostheses. Conversely, the development of new haptic interfaces offers touch scientists powerful new tools for systematically producing and controlling haptic or multisensory stimuli in innovative ways never previously possible.

\section{AUTHOR NOTE}

This article was financially supported by grants to S.J.L. from the Canadian Institutes of Health Research (CIHR) and the Natural Sciences and Engineering Research Council of Canada (NSERC) and to R.L.K. from the National Science Foundation (Grant BCS-0745328). We thank Cheryl Hamilton in the Touch Lab at Queen's University for assisting in the preparation of the manuscript. Correspondence concerning this article should be addressed to S. J. Lederman, Department of Psychology, Queen's University, Kingston, ON, K7L 3N6 Canada (e-mail: susan .lederman@queensu.ca) or to R. L. Klatzky, Department of Psychology, Carnegie Mellon University, Pittsburgh, PA 15213 (e-mail: klatzky@ andrew.cmu.edu).

\section{REFERENCES}

Amazeen, E. L., \& Turvey, M. T. (1996). Weight perception and the haptic size-weight illusion are functions of the inertia tensor. Journal of Experimental Psychology: Human Perception \& Performance, 22, 213-232.

Amedi, A., Jacobson, G., Hendler, T., Malach, R., \& Zohary, E. (2002). Convergence of visual and tactile shape processing in the human lateral occipital complex. Cerebral Cortex, 12, 1202-1212.

Amedi, A., Malach, R., Hendler, T., Peled, S., \& Zohary, E. (2001). Visuo-haptic object-related activation in the ventral visual pathway. Nature Neuroscience, 4, 324-330.

Anderson, N. H. (1974). Algebraic models in perception. In E. Carterette \& M. Friedman (Eds.), Handbook of perception II (pp. 215-298). New York: Academic Press.

Armstrong, L., \& Marks, L. E. (1999). Haptic perception of linear extent. Perception \& Psychophysics, 61, 1211-1226.

Bensmaïa, S. J., \& Hollins, M. (2003). The vibrations of texture. Somatosensory \& Motor Research, 20, 33-43.

Bensmaïa, S. [J.], \& Hollins, M. (2005). Pacinian representations of fine surface texture. Perception \& Psychophysics, 67, 842-854.

Bensmaïa, S. [J.], Hollins, M., \& YAU, J. (2005). Vibrotactile intensity and frequency information in the Pacinian system: A psychophysical model. Perception \& Psychophysics, 67, 828-841.

Berger, C., \& Hatwell, Y. (1993). Dimensional and overall similarity classifications in haptics: A developmental study. Cognitive Development, 8, 495-516.

Bergmann Tiest, W., \& Kappers, A. (2009). Tactile perception of thermal diffusivity. Attention, Perception, \& Psychophysics, 71, 481-489.

Biederman, I. (1987). Recognition by components: A theory of human image understanding. Psychological Review, 94, 115-147.

Blake, D. T., Hsiao, S. S., \& Johnson, K. O. (1997). Neural coding mechanisms in tactile pattern recognition: The relative contributions of slowly and rapidly adapting mechanoreceptors to perceived roughness. Journal of Neuroscience, 17, 7480-7489.

Blake, R., Sobel, K. V., \& James, T. W. (2004). Neural synergy between kinetic vision and touch. Psychological Science, 15, 397-402.

Blankenburg, F., Ruff, C. C., Deichmann, R., Rees, G., \& Driver, J. (2006). The cutaneous rabbit illusion affects human primary sensory cortex somatotopically. PLoS Biology, 4, e69. doi:10.1371/journal .pbio.0040069

BorING, E. G. (1942). Sensation and perception in the history of experimental psychology. New York: Appleton-Century-Crofts.

Brodie, E. E., \& Ross, H. E. (1984). Sensorimotor mechanisms in weight discrimination. Perception \& Psychophysics, 36, 477-481.

Buonomano, D. V., \& Merzenich, M. M. (1998). Cortical plasticity: From synapses to maps. Annual Review of Neuroscience, 21, 149-186.

BurTt, H. E. (1917). Tactual illusions of movement. Journal of Experimental Psychology: General, 2, 371-385.

CAscio, C. J., \& Sathian, K. (2001). Temporal cues contribute to tactile perception of roughness. Journal of Neuroscience, 21, 5289-5296.

Chan, J. S., \& Newell, F. N. (2008). Behavioral evidence for taskdependent "what" versus "where" processing within and across modalities. Perception \& Psychophysics, 70, 36-49.

Charpentier, A. (1891). Analyse experimentale de quelques éléments de la sensation de poids [Experimental study of some aspects of weight perception]. Archives de Physiologie Normales et Pathologiques, 1, 122-135.

Cheng, M. F. (1968). Tactile-kinesthetic perception of length. American Journal of Psychology, 81, 74-82.

Cinel, C., Humphreys, G. W., \& Poli, R. (2002). Cross-modal illusory conjunctions between vision and touch. Journal of Experimental Psychology: Human Perception \& Performance, 28, 1243-1266.

CraIG, J. C. (1999). Grating orientation as a measure of tactile spatial acuity. Somatosensory \& Motor Research, 16, 197-206.

DAvidson, P. W. (1972). Haptic judgments of curvature by blind and sighted humans. Journal of Experimental Psychology: General, 93, 43-55.

Deibert, E., Kraut, M., Kremen, S., \& Hart, J. (1999). Neural pathways in tactile object recognition. Neurology, 52, 1413-1417.

Dijkerman, H. C., \& De HaAn, E. H. F. (2007). Somatosensory processes subserving perception and action. Behavioral \& Brain Sciences, 30, 189-201.

EdIN, B. B., \& JoHANSSON, N. (1995). Skin strain patterns provide kinaesthetic information to the human central nervous system. Journal of Physiology, 487, 243-251.

Ellis, R. R., \& Lederman, S. J. (1998). The golf-ball illusion: Evidence for top-down processing in weight perception. Perception, 27, 193-202.

Ellis, R. R., \& Lederman, S. J. (1999). The material-weight illusion revisited. Perception \& Psychophysics, 61, 1564-1576.

ERnst, M. O., \& BANKs, M. S. (2002). Humans integrate visual and haptic information in a statistically optimal fashion. Nature, 415, 429-433.

Flach, R., \& HaggaRd, P. (2006). The cutaneous rabbit revisited. Journal of Experimental Psychology: Human Perception \& Performance, 32, 717-732.

Gallace, A., Auvray, M., Tan, H. Z., \& Spence, C. (2006). When visual transients impair tactile change detection: A novel case of crossmodal change blindness? Neuroscience Letters, 398, 280-285.

GandeVIa, S. C. (1996). Kinesthesia: Roles for afferent signals and motor commands. In L. B. Rowell \& J. T. Shepherd (Eds.), Handbook of physiology: Section 12. Exercise: Regulation and integration of multiple systems (pp. 128-172). New York: Oxford University Press.

Geldard, F. A. (1975). Sensory saltation: Metastability in the perceptual world. Oxford: Erlbaum.

Geldard, F. A., \& Sherrick, C. E. (1972). The cutaneous "rabbit": A perceptual illusion. Science, 178, 178-179. 
Gentaz, E., Baud-Bovy, G., \& Luyat, M. (2008). The haptic perception of spatial orientations. Experimental Brain Research, 187, 331-348.

Gentaz, E., \& Hatwell, Y. (1995). The haptic "oblique effect" in children's and adults' perception of orientation. Perception, 24, 631-646.

GESCHEIDER, G. A. (1974). Effects of signal probability on vibrotactile signal recognition. Perceptual \& Motor Skills, 38, 15-23.

Gibson, J. J. (1962). Observations on active touch. Psychological Review, 69, 477-491.

GoldreICH, D. (2007). A Bayesian perceptual model replicates the cutaneous rabbit and other tactile spatiotemporal illusions. PLOS ONE, 2, e333.

GoldReICH, D., \& Kanics, I. M. (2003). Tactile acuity is enhanced in blindness. Journal of Neuroscience, 23, 3439-3445.

Goodwin, A. W., Macefield, V. G., \& Bisley, J. W. (1997). Encoding of object curvature by tactile afferents from human fingers. Journal of Neurophysiology, 78, 2881-2888.

Grant, A. C., Thiagarajah, M. C., \& Sathian, K. (2000). Tactile perception in blind Braille readers: A psychophysical study of acuity and hyperacuity using gratings and dot patterns. Perception \& Psychophysics, 62, 301-312.

Hagen, M. C., Zald, D. H., Thornton, T. A., \& Pardo, J. V. (2002). Somatosensory processing in the human inferior prefrontal cortex. Journal of Neurophysiology, 88, 1400-1406.

Helbig, H. B., \& ERnst, M. O. (2007). Knowledge about a common source can promote visual-haptic integration. Perception, 36, 15231533.

Heller, M. A., Calcaterra, J. A., Burson, L. L., \& Green, S. L. (1997). The tactual horizontal-vertical illusion depends on radial motion of the entire arm. Perception \& Psychophysics, 59, 1297-1311.

Heller, M. A., \& Joyner, T. D. (1993). Mechanisms in the haptic horizontal-vertical illusion: Evidence from sighted and blind subjects. Perception \& Psychophysics, 53, 422-428.

Helson, H., \& King, S. M. (1931). The tau effect: An example of psychological relativity. Journal of Experimental Psychology, 14, 202-217.

Hertenstein, M. J., Keltner, D., App, B., Bulleit, B., \& Jaskolka, A. R. (2006). Touch communicates distinct emotions. Emotion, 6 $528-533$.

Ho, H.[-N.], \& JoNEs, L. A. (2004). Material identification using real and simulated thermal cues. Proceedings of the 26th Annual International Conference of the IEEE Engineering in Medicine and Biology Society (pp. 2462-2465). Los Alamitos, CA: IEEE Computer Society.

Ho, H.-N., \& Jones, L. A. (2006). Contribution of thermal cues to material discrimination and localization. Perception \& Psychophysics, 68 , 118-128.

Hollins, M., Bensmaïa, S. J., \& Risner, S. R. (1998). The duplex theory of tactile texture perception. Proceedings of the 14th Annual Meeting of the International Society for Psychophysics (pp. 115-121). Quebec: International Society for Psychophysics.

Hollins, M., Bensmaïa, S. J., \& WashbuRn, S. (2001). Vibrotactile adaptation impairs discrimination of fine, but not coarse, textures. Somatosensory \& Motor Research, 18, 253-262.

Howard, I., \& Templeton, W. (1966). Human spatial orientation. Oxford: Wiley.

HUNTER, I. M. L. (1954). Tactile-kinaesthetic perception of straightness in blind and sighted humans. Quarterly Journal of Experimental Psychology, 6, 149-154

James, T. W., Humphrey, G. K., Gati, J. S., Servos, P., Menon, R. S., \& Goodale, M. A. (2002). Haptic study of three-dimensional objects activates extrastriate visual areas. Neuropsychologia, 40, 1706-1714.

James, T. W., Servos, P., Kilgour, A. R., Huh, E. J., \& Lederman, S. (2006). The influence of familiarity on brain activation during haptic exploration of 3-D facemasks. Neuroscience Letters, 397, 269-273.

Johansson, R. S., LANDSTröM, U., \& LundSTRÖM, R. (1982). Responses of mechanoreceptive afferent units in the glabrous skin of the human hand to sinusoidal skin displacements. Brain Research, 244, 17-25.

Johansson, R. S., \& VALLBo, A. B. (1983). Tactile sensory coding in the glabrous skin of the human hand. Trends in Neurosciences, 6, 27-32.

JoHnson, K. O. (2001). The roles and functions of cutaneous mechanoreceptors. Current Opinion in Neurobiology, 11, 455-461.

Johnson, K. O., \& Hsiao, S. S. (1994). Evaluation of the relative roles of slowly and rapidly adapting afferent fibers in roughness perception. Canadian Journal of Physiology \& Pharmacology, 72, 488-497.

Johnson, K. O., \& Lamb, G. D. (1981). Neural mechanisms of spatial tactile discrimination: Neural patterns evoked by braille-like dot patterns in the monkey. Journal of Physiology, 310, 117-144.

Johnson, K. O., \& Phillips, J. R. (1981). Tactile spatial resolution. I. Two-point discrimination, gap detection, grating resolution, and letter recognition. Journal of Neurophysiology, 46, 1177-1191.

JONES, L. A., \& Ho, H.-N. (2008). Warm or cool, large or small? The challenge of thermal displays. IEEE Transactions on Haptics, 1, 53-70.

Jones, L. A., \& Lederman, S. J. (2006). Human hand function. New York: Oxford University Press.

JousmäKI, V., \& HARI, R. (1998). Parchment-skin illusion: Sound-biased touch. Current Biology, 8, R190.

Kandel, E., Schwartz, J., \& Jessell, T. (2000). Principles of neural science. New York: McGraw-Hill.

Kappers, A. M. L. (2003). Large systematic deviations in a bimanual parallelity task: Further analysis of contributing factors. Acta Psychologica, 114, 131-145.

KAPPERS, A. M. L. (2007). Haptic spatial processing: Allocentric and egocentric reference frames. Canadian Journal of Experimental Psychology, 61, 208-218.

Katz, D. (1989). The world of touch (L. E. Krueger, Trans.). Hillsdale, NJ: Erlbaum. (Original work published 1925)

Kitada, R., Johnsrude, I., Kochiyama, T., \& Lederman, S. J. (2009). Functional specialization and convergence in the occipito-temporal cortex supporting haptic and visual identification of human faces and body parts: An fMRI study. Journal of Cognitive Neuroscience, 21, 1-19.

Kitada, R., Kito, T., Saito, D. N., Kochiyama, T., Matsumura, M., Sadato, N., \& Lederman, S. J. (2006). Multisensory activation of the intraparietal area when classifying grating orientation: A functional magnetic resonance imaging study. Journal of Neuroscience, 26, 7491-7501.

KLATZKY, R. L. (1998). Allocentric and egocentric spatial representations: Definitions, distinctions, and interconnections. In C. Freksa, C. Habel, \& K. F. Wender (Eds.), Spatial cognition (pp. 1-17). Berlin Springer.

Klatzky, R. L., \& Lederman, S. J. (1993). Toward a computational model of constraint-driven exploration and haptic object identification. Perception, 22, 597-621

Klatzky, R. L., \& Lederman, S. J. (1995). Identifying objects from a haptic glance. Perception \& Psychophysics, 57, 1111-1123.

Klatzky, R. L., \& Lederman, S. J. (2003). Representing spatial location and layout from sparse kinesthetic contacts. Journal of Experimental Psychology: Human Perception \& Performance, 29, 310-325.

KLATZKY, R. L., \& Lederman, S. J. (2007). Object recognition by touch. In J. J. Rieser, D. Ashmead, F. Ebner, \& A. Corn (Eds.), Blindness and brain plasticity in navigation and object perception (pp. 185-207). Mahwah, NJ: Erlbaum.

Klatzky, R. L., Lederman, S. J., \& Metzger, V. A. (1985). Identifying objects by touch: An "expert system." Perception \& Psychophysics, 37, 299-302.

Klatzky, R. L., Lederman, S. J., \& Reed, C. (1987). There's more to touch than meets the eye: The salience of object dimensions for touch with and without vision. Journal of Experimental Psychology: General, 116, 356-369.

Klatzky, R. L., Loomis, J. M., Lederman, S. J., Wake, H., \& FuJITA, N. (1993). Haptic identification of objects and their depictions. Perception \& Psychophysics, 54, 170-178.

KNIBESTöl, M., \& VALLBO, A. B. (1970). Single unit analysis of mechanoreceptor activity from the human glabrous skin. Acta Physiologica Scandinavica, 80, 178-195.

KossLyn, S. M., \& Thompson, W. L. (1993). When is early visual cortex activated during visual mental imagery? Psychological Bulletin, 129, 723-746.

Lacey, S., Campbell, C., \& Sathian, K. (2007). Vision and touch: Multiple or multisensory representations of objects? Perception, 36, 1513-1521.

Lakatos, S., \& Marks, L. E. (1999). Haptic form perception: Relative salience of local and global features. Perception \& Psychophysics, 61, 895-908

LaMotte, R. H., \& Srinivasan, M. A. (1993). Responses of cutane- 
ous mechanoreceptors to the shape of objects applied to the primate fingerpad. Acta Psychologica, 84, 41-52.

Lechelt, E. C., Eliuk, J., \& TAnne, G. (1976). Perceptual orientation asymmetries: A comparison of visual and haptic space. Perception \& Psychophysics, 20, 463-469.

LeCHELT, E. C., \& VerENKA, A. (1980). Spatial anisotropy in intramodal and cross-modal judgments of stimulus orientation: The stability of the oblique effect. Perception, 9, 581-589.

Lederman, S. J. (1974). Tactile roughness of grooved surfaces: The touching process and effects of macro- and microsurface structure. Perception \& Psychophysics, 16, 385-395.

LEDERMAN, S. J. (1983). Tactual roughness perception: Spatial and temporal determinants. Canadian Journal of Psychology, 37, 498-511.

LEDERMAN, S. J. (1991). Skin and touch. Encyclopedia of human biology (Vol. 7, pp. 51-63). San Diego: Academic Press.

Lederman, S. J., Kilgour, A., Kitada, R., Klatzky, R. L., \& HamilTON, C. (2007). Haptic face processing. Canadian Journal of Psychology, 61, 230-241.

Lederman, S. J., \& KlatzKy, R. L. (1987). Hand movements: A window into haptic object recognition. Cognitive Psychology, 19, 342-368.

Lederman, S. J., \& KlatzKy, R. L. (1990). Haptic classification of common objects: Knowledge-driven exploration. Cognitive Psychology, 22, 421-459.

LEDERMAN, S. J., \& KLATZKY, R. L. (1997). Relative availability of surface and object properties during early haptic processing. Journal of Experimental Psychology: Human Perception \& Performance, 23, 1680-1707.

Lederman, S. J., \& KLatzKy, R. L. (1999). Sensing and displaying spatially distributed fingertip forces in haptic interfaces for teleoperator and virtual environment systems. Presence: Teleoperators \& Virtual Environments, 8, 86-103.

Lederman, S. J., \& KlatzKy, R. L. (2004). Haptic identification of common objects: Effects of constraining the manual exploration process. Perception \& Psychophysics, 66, 618-628.

Lederman, S. J., \& KlatzKy, R. L. (2009). Human haptics. In L. R. Squire (Ed. in Chief), Encyclopedia of neuroscience (Vol. 5, pp. 1118). San Diego: Academic Press.

Lederman, S. J., Klatzky, R. L., \& Barber, P. O. (1985). Spatial and movement-based heuristics for encoding pattern information through touch. Journal of Experimental Psychology: General, 114, 33-49.

Lederman, S. J., Klatzky, R. L., Chataway, C., \& Summers, C. D. (1990). Visual mediation and the haptic recognition of two-dimensional pictures of common objects. Perception \& Psychophysics, 47, 54-64.

Lederman, S. J., Klatzky, R. L., Rennert-May, E., Lee, J. H., NG, K., \& Hamilton, C. (2008). Haptic processing of facial expressions of emotion in 2D raised-line drawings. IEEE Transactions on Haptics, 1, 27-38.

Lederman, S. J., Loomis, J. M., \& Williams, D. A. (1982). The role of vibration in the tactual perception of roughness. Perception \& Psychophysics, 32, 109-116.

Lederman, S. J., Summers, C., \& Klatzky, R. L. (1996). Cognitive salience of haptic object properties: Role of modality-encoding bias. Perception, 25, 983-998.

Lederman, S. J., \& TAYLOR, M. M. (1972). Fingertip force, surface geometry, and the perception of roughness by active touch. Perception \& Psychophysics, 12, 401-408.

Lederman, S. J., Thorne, G., \& Jones, B. (1986). Perception of texture by vision and touch: Multidimensionality and intersensory integration. Journal of Experimental Psychology: Human Perception \& Performance, 12, 169-180.

Legge, G. E., Madison, C., Vaughn, B. N., Cheong, A. M. Y., \& MiLler, J. C. (2008). Retention of high tactile acuity throughout the life span in blindness. Perception \& Psychophysics, 70, 1471-1488.

LÖFVENBERG, J., \& JOHANSSON, R. S. (1984). Regional differences and interindividual variability in sensitivity to vibration in the glabrous skin of the human hand. Brain Research, 301, 65-72.

Löken, L. S., Wessberg, J., Morrison, I., McGlone, F., \& Olausson, H. (2009). Coding of pleasant touch by unmyelinated afferents in humans. Nature Neuroscience, 12, 547-548.

Louw, S., Kappers, A. M. L., \& Koenderink, J. J. (2000). Haptic detection thresholds of Gaussian profiles over the whole range of spatial scales. Experimental Brain Research, 132, 369-374.
Malach, R., Reppas, J. B., Benson, R. R., Kwong, K. K., Jiang, H., KenNEDY, W. A., ET AL. (1995). Object-related activity revealed by functional magnetic resonance imaging in human occipital cortex. Proceedings of the National Academy of Sciences, 92, 8135-8139.

Marchetti, F. M., \& Lederman, S. J. (1983). The haptic radialtangential effect: Two tests of Wong's "moments-of-inertia" hypothesis. Bulletin of the Psychonomic Society, 21, 43-46.

MARKs, D. F. (1973). Visual imagery differences in the recall of pictures. British Journal of Psychology, 64, 17-24.

Marr, D. (1982). Vision. San Francisco: W. H. Freeman.

McGlone, F., Vallbo, A. B., Olausson, H., Löken, L., \& WessBERG, J. (2007). Discriminative touch and emotional touch. Canadian Journal of Experimental Psychology/Revue Canadienne de Psychologie Expérimentale, 61, 173-183.

Meftah, E. M., Belingard, L., \& Chapman, E. (2000). Relative effects of the spatial and temporal characteristics of scanned surfaces on human perception of tactile roughness using passive touch. Experimental Brain Research, 132, 351-361.

Merabet, L. B., Hamilton, R., Schlaug, G., Swisher, J. D., Kiriakopoulos, E. T., Pitskel, N. B., ET AL. (2008). Rapid and reversible recruitment of early visual cortex for touch. PLoS ONE, 27, e3046.

Merzenich, M. M., KaAs, J. H., Wall, J., Sur, M., \& Lin, C.-S. (1978). Double representation of the body surface within cytoarchitectonic Areas $3 \mathrm{~b}$ and 1 in "S1" in the owl monkey (Aotus trivigatus). Journal of Comparative Neurology, 191, 41-73.

Millar, S. (1976). Spatial representation by blind and sighted children. Journal of Experimental Child Psychology, 21, 460-479.

MillaR, S. (1994). Understanding and representing space: Theory and evidence from studies with blind and sighted children. Oxford: Oxford University Press, Clarendon Press.

Olausson, H., Lamarre, Y., Backlund, H., Morin, C., Wallin, B. G., STARCK, G., ET AL. (2002). Unmyelinated tactile afferents signal touch and project to insular cortex. Nature Neuroscience, 5, 900-904.

Olausson, H., Wessberg, J., \& KaKuda, N. (2000). Tactile directional sensibility: Peripheral neural mechanisms in man. Brain Research, 866, 178-187.

Overvliet, K. E., Smeets, J. B. J. \& Brenner, E. (2007). Parallel and serial search in haptics. Perception \& Psychophysics, 69, 1059-1069.

Pascual-Leone, A., \& Hamilton, R. H. (2001). The metamodal organization of the brain. Progress Brain Research, 134, 427-445.

Pietrini, P., Furey, M. L., Ricciardi, E., Gobbini, M. I., Wu, W. H., Cohen, L., ET AL. (2004). Beyond sensory images: Object-based representation in the human ventral pathway. Proceedings of the National Academy of Sciences, 101, 5658-5663.

Plaisier, M. A., Bergmann Tiest, W. M., \& Kappers, A. M. L. (2008) Haptic pop-out in a hand sweep. Acta Psychologica, 128, 368-377.

PonT, S. C. (1997). Haptic curvature comparison. Unpublished doctoral dissertation, Helmholz Instituut, Utrecht.

Pont, S. C., Kappers, A. M. L., \& Koenderink, J. J. (1997). Haptic curvature discrimination at several regions of the hand. Perception \& Psychophysics, 59, 1225-1240.

Pont, S. C., KapPers, A. M. L., \& KoEnderinK, J. J. (1998). Anisotropy in haptic curvature and shape perception. Perception, 27, 573-589.

Pont, S. C., Kappers, A. M. L., \& KoenderinK, J. J. (1999). Similar mechanisms underlie curvature comparison by static and dynamic touch. Perception \& Psychophysics, 61, 874-894

Reed, C. L., Klatzky, R. L., \& Halgren, E. (2005).What vs. where in touch: An fMRI study. NeuroImage, 25, 718-726.

Reed, C. L., Shoham, S., \& Halgren, E. (2004). Neural substrates of tactile object recognition: An fMRI study. Human Brain Mapping, 21, 236-246.

Rensink, R. A., O'Regan, J. K., \& Clark, J. J. (1997). To see or not to see: The need for attention to perceive changes in scenes. Psychological Science, 8, 368-373.

RocK, I., \& VICTOR, J. (1964). Vision and touch: An experimentally created conflict between the two senses. Science, 143, 594-596.

SANDERS, A. F. J., \& KaPPERS, A. M. L. (2008). Curvature affects haptic length perception. Acta Psychologica, 129, 340-351.

Sathian, K., \& Lacey, S. (2007). Tactile perception: Beyond somatosensory cortex. Canadian Journal of Experimental Psychology, 61, 254-264.

Sathian, K., \& Lacey, S. (2008). Visual cortical involvement during 
tactile perception in blind and sighted individuals. In J. J. Rieser, D. H. Ashmead, F. F. Ebner, \& A. L. Corn (Eds.), Blindness and brain plasticity in navigation and object perception (pp. 113-125). Mahwah, NJ: Erlbaum.

Sathian, K., \& Zangaladze, A. (2001). Feeling with the mind's eye: The role of visual imagery in tactile perception. Optometry \& Vision Science, 78, 276-281.

Sathian, K., Zangaladze, A., Hoffman, J. M., \& Grafton, S. T. (1997). Feeling with the mind's eye. NeuroReport, 8, 3877-3881.

Sherrick, C. E., \& Cholewiak, R. W. (1986). Cutaneous sensitivity. In K. Boff, L. Kaufman, \& J. Thomas (Eds.), Handbook of perception and human performance (pp. 1-70). New York: Wiley.

Sherrick, C. E., \& Rogers, R. (1966). Apparent haptic movement. Perception \& Psychophysics, 1, 175-180.

Shimono, K., Higashiyama, A., \& Tam, W. J. (2001). Location of the egocenter in kinesthetic space. Journal of Experimental Psychology: Human Perception \& Performance, 27, 848-861.

Spence, C., Nicholls, M. E. R., \& Driver, J. (2001). The cost of expecting events in the wrong sensory modality. Perception \& Psychophysics, 63, 330-336.

SQuire, L. R. (ED.) (2009). Encyclopedia of neuroscience. San Diego: Academic Press.

SRINIVASAN, M. A., \& LAMotTe, R. H. (1995). Tactual discrimination of softness. Journal of Neurophysiology, 73, 88-101

Stevens, J. C. (1979). Thermal intensification of touch sensation: Further extensions of the Weber phenomenon. Sensory Processes, 3, 240-248.

Stevens, J. C. (1991). Thermal sensibility. In M. A. Heller \& W. Schiff (Eds.), The psychology of touch (pp. 61-90). Hillsdale, NJ: Erlbaum.

Stevens, J. C., \& Patterson, M. Q. (1995). Dimensions of spatial acuity in the touch sense: Changes over the life span. Somatosensory \& Motor Research, 12, 29-47.

Stoeckel, M. C., Weder, B., Binkofski, F., Buccino, G., Shah, N. J., \& SEITZ, R. J. (2003). A fronto-parietal circuit for tactile object discrimination: An event-related fMRI study. NeuroImage, 19, 11031114.

Stoesz, M., Zhang, M., Weisser, V. D., Prather, S. C., Mao, H., \& SATHIAN, K. (2003). Neural networks active during tactile form perception: Common and differential activity during macrospatial and microspatial tasks. International Journal of Psychophysiology, 50, 41-49.

TAYLOR, J. L. (2009). Proprioception. In L. R. Squire (Ed.), Encyclopedia of neuroscience (Vol. 7, pp. 1143-1149). Oxford: Academic Press.

TAYLOR, M. M., \& LEDERMAN, S. J. (1975). Tactile roughness of grooved surfaces: A model and the effect of friction. Perception \& Psychophysics, 17, 23-36.

Treisman, A. M., \& Gelade, G. (1980). A feature-integration theory of attention. Cognitive Psychology, 12, 97-136.

Treisman, A. [M.], Sykes, M., \& Gelade, G. (1977). Selective attention and stimulus integration. In S. Dornic (Ed.), Attention and performance VI (pp. 333-361). Hillsdale, NJ: Erlbaum.

Trojan, J., Stolle, A. M., Kleinboehl, D., Morch, C. D., ArendtNielsen, L., \& HoelzL, R. (2006). The saltation illusion demon- strates integrative processing of spatiotemporal information in thermoceptive and nociceptive networks. Experimental Brain Research, 170, 88-96.

UnGERLEIDER, L. G., \& MishKIN, M. (1982) Two cortical visual systems. In D. J. Ingle, M. A. Goodale, \& R. J. W. Mansfield (Eds.), Analysis of visual behavior (pp. 549-586). Cambridge, MA: MIT Press.

vaN DER Horst, B. J., \& KAPPERS, A. M. L. (2008). Haptic curvature comparison of convex and concave shapes. Perception, 37, 11371151.

Vega-Bermudez, F., \& Johnson, K. O. (2004). Fingertip skin conformance accounts, in part, for differences in tactile spatial acuity in young subjects, but not for the decline in spatial acuity with aging. Perception \& Psychophysics, 66, 60-67.

Verrillo, R. T., Bolanowski, S. J., Checkosky, C. M., \& McGlone, F (1998). Effects of hydration on tactile sensation. Somatosensory \& Motor Research, 15, 93-108.

VIERCK, C. J. (1979). Comparisons of punctate, edge and surface stimulation of peripheral slowly-adapting, cutaneous, afferent units of cats. Brain Research, 175, 155-159.

Vitevitch, M. S. (2003). Change deafness: The inability to detect changes between two voices. Journal of Experimental Psychology: Human Perception \& Performance, 29, 333-342.

Vogels, I. M. L. C., Kappers, A. M. L., \& KoenderinK, J. J. (1999). Influence of shape on haptic curvature perception. Acta Psychologica, 100, 267-289.

WeINSTEIN, S. (1968). Intensive and extensive aspects of tactile sensitivity as a function of body part, sex, and laterality. In D. R. Kenshalo (Ed.), The skin senses (pp. 195-222). Springfield, IL: Thomas.

WestLING, G., \& Johansson, R. S. (1987). Responses in glabrous skin mechanoreceptors during precision grip in humans. Experimental Brain Research, 66, 128-140.

WheAt, H., \& Goodwin, A. W. (2001). Tactile discrimination of edge shape: Limits on spatial resolution imposed by parameters of the peripheral neural population. Journal of Neuroscience, 21, 77517763.

Williams, L. E., \& BARGH, J. A. (2008). Experiencing physical warmth promotes interpersonal warmth. Science, 322, 606-607.

Wolfe, J. M., Kluender, K. R., Levi, D. M., Bartoshuk, L. M., Herz, R. S., Klatzky, R. L., \& Lederman, S. J. (2008). Sensation and perception (2nd ed.). Sunderland, MA: Sinauer.

WoNG, T. S. (1977). Dynamic properties of radial and tangential movements as determinants of the haptic horizontal-vertical illusion with an "L" figure. Journal of Experimental Psychology: Human Perception \& Performance, 3, 151-164.

Zangaladze, A., Epstein, C. M., Grafton, S. T., \& Sathian, K. (1999). Involvement of visual cortex in tactile discrimination of orientation. Nature, 401, 587-590.

Zhang, M., Weisser, V. D., Stilla, R., Prather, S. C., \& Sathian, K. (2004). Multisen `sory cortical processing of object shape and its relation to mental imagery. Cognitive, Affective, \& Behavioral Neuroscience, 4, 251-259.

\section{APPENDIX}

\section{General Reference Articles and Books}

Gescheider, G. A., Wright, J. H., \& Verrillo, R. T. (2008). Information-processing channels in the tactile sensory system: A psychophysical and physiological analysis. New York: Psychology Press.

Gibson, J. J. (1966). The senses considered as perceptual systems. Boston: Houghton Mifflin.

Greenspan, J. D., \& Bolanowski, S. J. (1996). The psychophysics of tactile perception and its peripheral physiological basis (chap. 2). In L. Kruger (Ed.), Pain and touch (pp. 25-103). San Diego: Academic Press.

Grunwald, M. (Ed.) (2008). Human haptic perception: Basics and applications. Basel: Birkhäuser.

Hatwell, Y., Streri, A., \& Gentz, E. (Eds.) (2003). Touching for knowing. Amsterdam: Benjamins.

Heller, M., \& Ballesteros, S. (2006). Touch and blindness: Psychology and neuroscience. Mahwah, NJ: Erlbaum.

Johansson, R. S., \& Flanagan, R. (2009). Coding and use of tactile signals from the fingertips in object manipulation tasks. Nature Reviews Neuroscience, 10, 345-359.

Jones, L. A., \& Lederman, S. J. (2006). Human hand function. New York: Oxford University Press. 


\section{APPENDIX (Continued)}

Katz, D. (1989). The world of touch (L. E. Krueger, Trans.). Hillsdale, NJ: Erlbaum. (Original work published 1925)

Klatzky, R. L., \& Lederman, S. J. (2003). Touch. In I. B. Weiner (Ed. in Chief) \& A. F. Healy \& R. W. Proctor (Eds.), Handbook of psychology: Vol. 4. Experimental psychology (pp. 147-176). New York: Wiley.

Lederman, S. J., \& Klatzky, R. L. (2004). Multisensory texture perception. In G. Calvert, C. Spence, \& B. Stein (Eds.), Handbook of multisensory processes (pp. 107-122). Cambridge, MA: MIT Press.

Lederman, S. J., \& Klatzky, R. L. (Eds.) (2007). New directions in touch [Special issue]. Canadian Journal of Psychology, 61(3).

Lederman, S. J., \& Klatzky, R. L. (2009). Human haptics. In L. R. Squire (Ed. in Chief), Encyclopedia of neuroscience (Vol. 5, pp. 11-18). San Diego: Academic Press.

Loomis, J. M., \& Lederman, S. J. (1986). Tactual perception. In K. Boff, L. Kaufman, \& J. Thomas (Eds.), Handbook of perception and human performance (pp. 31-41). New York: Wiley.

Révész, G. (1950). Psychology and art of the blind. London: Longmans, Green.

Rieser, J. J., Ashmead, D. H., Ebner, F. F., \& Corn, A. L. (2007). Blindness and brain plasticity in navigation and object perception. New York: Psychology Press.

Squire, L. R. (Ed. in Chief) (2009). Encyclopedia of neuroscience. San Diego: Academic Press.

Taylor, J. L. (2009). Proprioception. In L. R. Squire (Ed.), Encyclopedia of neuroscience (Vol. 7, pp.1143-1149). San Diego: Academic Press.

von Skramlik, E. R. (1937). Psychophysiologie der Tastsinne. Leipzig: Akademische Verlag.

Weber, E. H. (1978). The sense of touch (H. E. Ross, Trans.). London: Academic Press. (Original work published 1834)

Wolfe, J. M., Kluender, K. R., Levi, D. M., Bartoshuk, L. M., Herz, R. S., Klatzky, R. L., \& Lederman, S. J. (2008). Touch (chap. 12). In Sensation and perception (2nd ed., pp. 286-313). Sunderland, MA: Sinauer.

(Manuscript received April 8, 2009;

revision accepted for publication May 31, 2009.) 